\title{
Magnetohydrodynamic Augmented Propulsion Experiment
}

\author{
Ron J. Litchford ${ }^{1}$ \\ NASA Marshall Space Flight Center \\ John T. Lineberry ${ }^{2}$ \\ LyTec, $L L C$
}

\begin{abstract}
Over the past several years, efforts have been under way to design and develop an operationally flexible research facility for investigating the use of cross-field MHD accelerators as a potential thrust augmentation device for thermal propulsion systems. The baseline configuration for this high-power experimental facility utilizes a $1.5-\mathrm{MW}_{\mathrm{e}}$ multi-gas arc-heater as a thermal driver for a 2-MW $-\mathrm{MHD}_{\mathrm{e}}$ accelerator, which resides in a large-bore 2-tesla electromagnet. A preliminary design study using $\mathrm{NaK}$ seeded nitrogen as the working fluid led to an externally diagonalized segmented MHD channel configuration based on an expendable heat-sink design concept. The current status report includes a review of engineering/design work and performance optimization analyses and summarizes component hardware fabrication and development efforts, preliminary testing results, and recent progress toward full-up assembly and testing
\end{abstract}

\section{Introduction}

$\mathrm{M}$ AGNETOHYDRODYNAMIC (MHD) augmentation of thermal propulsion systems has been suggested as a plausible means of boosting exhaust velocity, and possibly improving overall specific energy attributes. In this way, one might hope to reduce fuel fraction and shrink vehicle size without sacrificing payload delivery capability. To obtain a meaningful improvement in fuel fraction, however, it can be shown that the electrical augmentation power must be greater in magnitude than the thermal power of the unaugmented source. Such considerations lead to some extremely daunting technical challenges, particularly in relation to the development of an on-board electrical power source with adequate power density characteristics. Nevertheless, several technological avenues can be identified that someday may lead to innovative compact high-power electrical energy sources possessing the required attributes, and exploratory pursuit of fundamental technical feasibility is not without credible justification. Moreover, MHD accelerator technology has potential dual use application in ground based hypersonic wind tunnel facilities where the electrical power source weight is of little or no concern.

The essential requirement for using electromagnetic acceleration techniques is that the exhaust jet from the thermal propulsion source be electrically conductive. In practice, this can be accomplished by seeding the combustor flow of a chemical rocket with an alkali metal vapor, such as $\mathrm{Cs}, \mathrm{Rb}, \mathrm{K}$ and associated compounds. Because alkali metals have a relatively low ionization potential, the energy consumed in fully ionizing the seed is only a small fraction of the available thermal energy. Furthermore, the relatively low plasma working temperature is compatible with existing materials and regenerative cooling techniques. Using energetic rocket fuels, this method is known to produce supersonic plasma flows with an electrical conductivity on the order of $10^{2} \mathrm{~S} / \mathrm{m}$, which is sufficient for evoking significant MHD interaction. At this level of MHD interaction, steady plasma acceleration is best invoked through externally imposed crossed electric and magnetic fields. This configuration gives rise to the so-called "Crossed Field MHD Accelerator" in which the imposed Lorentz body force accelerates the flow.

Small prototypes for this class of plasma accelerator have been designed and built, but almost exclusively from the standpoint of producing a hypersonic wind tunnel rather than a propulsive device. Testing with these prototype devices has clearly demonstrated flow acceleration, but diagnostic limitations have prevented complete delineation

\footnotetext{
${ }^{1}$ Project Principal Investigator, Thermal/Combustion Devices, Propulsion System Department.

${ }^{2}$ President \& CEO, Senior Member AIAA.
} 
of the fundamental physical phenomena. Many uncertainties remain including the relative importance of electromagnetic versus electrothermal effects, achievable accelerator efficiencies, achievable current densities, maximum sustainable axial electric field without inter-electrode arcing, effect of near-wall velocity overshoot phenomena, effect of micro-arcing in the cold electrode boundary layer, multi-terminal loading of a segmented Faraday channel versus two-terminal loading of a diagonal wall configuration, and thermal loading and erosive effects with respect to long-term channel survivability, to name a few.

Several years ago, NASA Marshall Space Flight Center initiated development of the Magnetohydrodynamic Augmented Propulsion Experiment (MAPX) for the purpose of resolving some of the critical technical issues associated with the use of MHD accelerators as thrust augmentation devices. A summary description of the project was previously published which included a thorough historical account of preceding MHD accelerator research programs, a detailed description of the experiment configuration, and results from a preliminary performance analysis and design study. ${ }^{[1]}$ Over the intervening years, the project has suffered numerous programmatic setbacks but has haltingly progressed, nevertheless, and has finally reached the point where all major pieces of hardware and test apparatus are available and in place. The purpose of this paper is to provide an updated project status report to include a review of engineering and design work, performance optimization analyses, component hardware fabrication and development efforts, preliminary testing results, and recent progress toward full-up assembly and testing.

\section{Experiment Development}

The MAPX facility adapts a traditional linear MHD flow-path configuration, as shown schematically in Fig. 1. First, the working fluid (i.e., $\mathrm{N}_{2}$ ) is heated in a $1.5-\mathrm{MW}_{\mathrm{e}}$ segmented multi-gas arc-heater to a stagnation temperature $\mathrm{T}_{0} \approx 4000-4500 \mathrm{~K}$ at a stagnation pressure $\mathrm{P}_{0} \approx 10 \mathrm{~atm}$. The hot gas then enters a mixing chamber where alkali metal seed (i.e., NaK) is injected into the flow stream after which it is expanded through a primary nozzle to a Mach number in the range of $\mathrm{M} \approx 1.25-1.5$. A $2-\mathrm{MW}_{\mathrm{e}} \mathrm{MHD}$ accelerator directly increases the energy and momentum of the flow, which is further diffused in a secondary nozzle to obtain the maximum possible jet velocity. The secondary nozzle exhausts into a large windowed test section equipped with a stinger mounted stagnation probe or

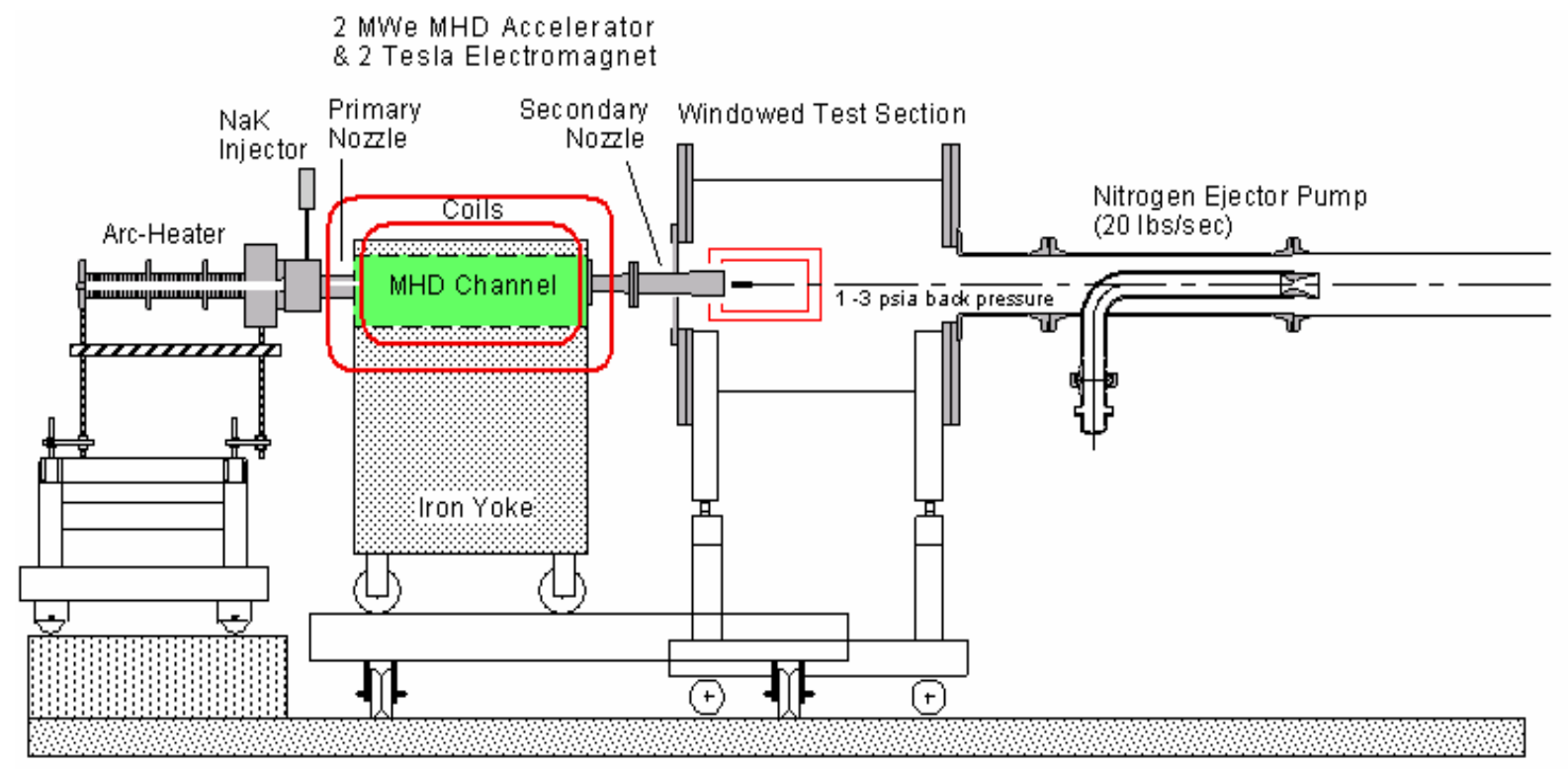

Figure 1. Schematic of the NASA MSFC MAPX facility. The major flow-path components are: (1) 1.5-MW arc-heater, (2) seed injector and mixing chamber, (3) primary expansion nozzle, (4) 2-MW $\mathrm{MWD}_{\mathrm{e}}$ accelerator channel and 2-tesla electromagnet, (5) secondary nozzle, (6) windowed test section, and (7) nitrogen driven ejector pump. 
aero model. The test section is attached to a nitrogen driven ejector pump designed to maintain a backpressure in the range of $1-3$ psia.

\section{A. Arc-Heater Thermal Driver \& Primary Nozzle}

The hyper-thermal stagnation conditions are generated by a $1.5-\mathrm{MW}_{\mathrm{e}}$ (nominal) segmented multi-gas arc-heater, which operates in a wall-stabilized constricted arc DC discharge mode. This device was originally developed by Aerotherm Corporation in Mountain View, CA more than 30 years ago, but was decommissioned and transferred to Marshall Space Flight Center (MSFC) in 1998 with the intent of supporting propulsion materials development and qualification testing, primarily solid motor nozzle materials. The system was never fully utilized as projected, however, and has therefore been generally available to support other R\&D test programs.

This particular arc-heater has a 1-inch internal bore diameter and follows the traditional segmentation design philosophy whereby alternating conductor/insulator wafers are stacked together to form the full length assembly, as illustrated in Fig. 2. The 3/8-inch thick heat conducting copper segments are water cooled and are separated by boron nitride insulators in stacked pack subassemblies, which are held securely together by four inconel tie rods. These subassembly packs are then attached in a sequential manner to form the full arc-heater column, which spans an overall length of about 1 meter in the three-pack configuration shown. The working gas is injected tangentially through four 0.048-inch jets in a Primary Gas Injection (PGI) segment near the rear of the arc-heater, and a DC arc discharge is established between a tungsten cathode button in the rear sealing flange and a copper anode ring at the arc-heater exhaust. A magnetic spin coil is located around the anode ring to induce continuous rotation of the arc attachment point. Facility schematics for the gas supply and cooling loop / calorimeter subsystems are shown in Fig. 3.
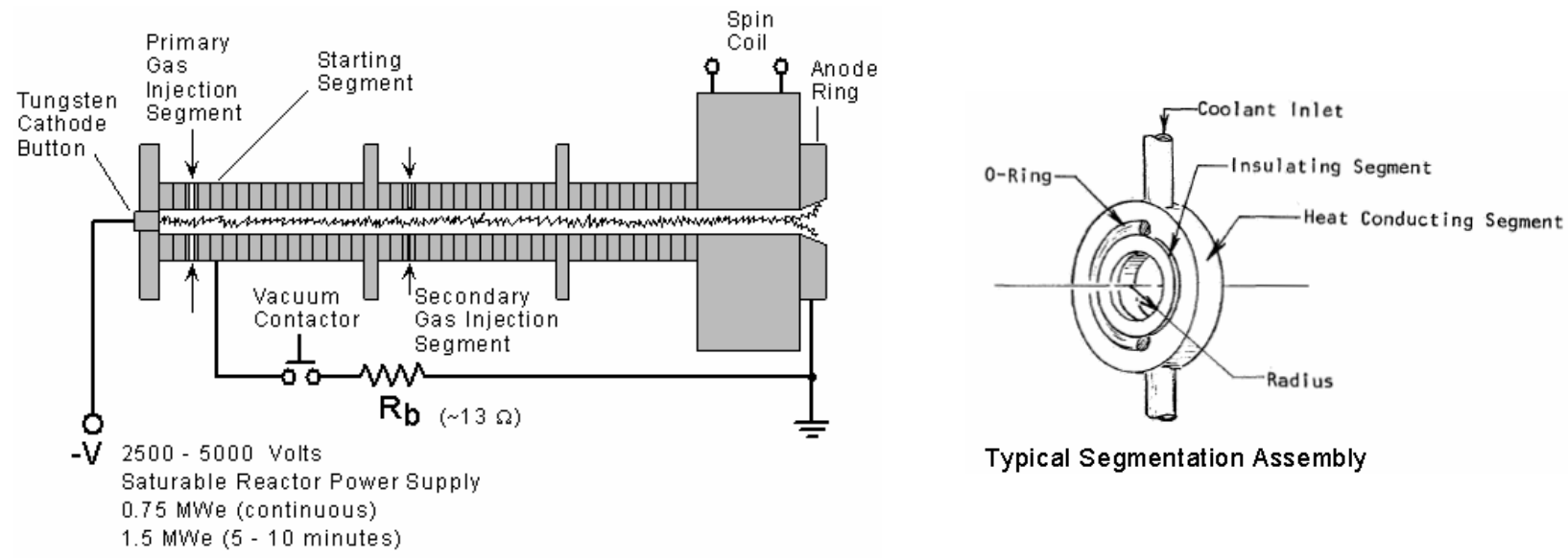

Typical Segmentation Assembly

Figure 2. Segmentation and assembly detail of the NASA MSFC 1-MW $\mathrm{H}_{\mathrm{e}}$ multi-gas arc-heater.

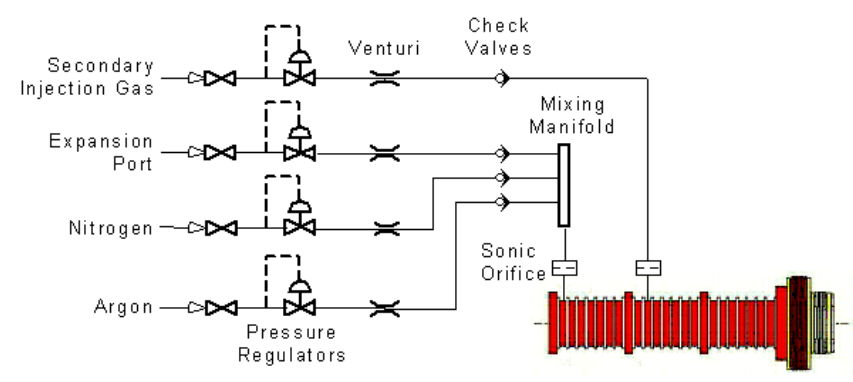

Gas Supply Schematic

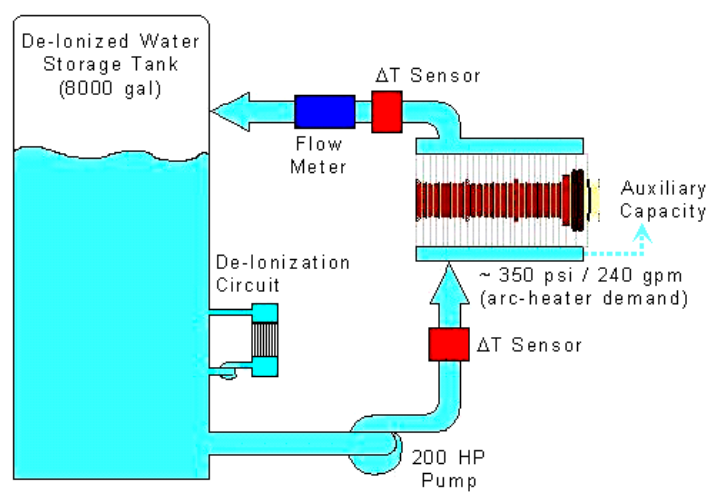

Cooling Loop / Calorimeter Schematic

Figure 3. Arc-heater facility schematics for gas supply and cooling loop / calorimeter subsystems. 
In order to start the device at atmospheric chamber pressure, a modest flow of argon is first introduced into the arc-heater and an initial gas discharge is established between the cathode button and a starting segment, which is located just downstream of the PGI segment. The anode power lead is then automatically switched from the starting segment to the anode ring by opening a vacuum contactor, which establishes a stable arc down the full length of the arc-heater. At this point, argon flow can be replaced with the desired working gas and the system can be ramped to the desired operating state.

The arc-heater is energized by a saturable reactor DC power supply which can sustain a continuous operating power of $0.75-\mathrm{MW}_{\mathrm{e}}$ on an indefinite basis and can deliver an intermittent power burst of $1.5-\mathrm{MW}_{\mathrm{e}}$ for 5 to 10 minutes. This power supply can be configured in either parallel mode (2500 volts open circuit) or series mode (5000 volts open circuit) as needed to match the internal impedance characteristics of the gas discharge, and for low impedance nitrogen operation, the power supply was therefore placed in parallel mode configuration. Powered conditions during MAPX experimental runs can be limited to a very short time duration (i.e., on the order of a second), and the arc-heater can therefore be operated at maximum burst electrical power level. The ability to operate at this extreme power condition yields the highest possible mass throughput, and serves as a means of maximizing channel size within geometric constraints imposed by the magnet bore.

Ideally, both the ionizing seed material and primary working fluid would be mixed and heated within the thermal source. This is not feasible with an arc-heater as it would dramatically reduced plasma resistivity, repress Joule heating, and result in severe discharge instabilities. Therefore, the best practical alternative is to inject an alkali metal seed material directly into the post-discharge region of the archeater and allow sufficient time for mixing upstream of the accelerating nozzle. For MAPX, we therefore decided to adapt a $\mathrm{NaK}$ aerosol injection scheme previously demonstrated in an MHD accelerator wind tunnel at the Central Institute of Aerohydrodynamics (TsAGI) in Russia.

Because NaK eutectic is a liquid metal under ambient conditions, the thermal management and injection system are greatly simplified. However, the material also introduces some major hazards and performance drawbacks. For example, $\mathrm{NaK}$ reacts violently upon contact with air resulting in the formation of oxides that could clog the flow path. This possibility necessitates the use of an inert purge gas before and after injection. Careful attention must be given to the injection location to achieve efficient mixing and to preclude the penetration of the seed into the discharge region. For complete vaporization of metal aerosols, this typically requires a mixing chamber having a residence time of $1-10 \mathrm{~ms}$. Furthermore, the NaK should be exceptionally pure $(\geq$ $99.99 \%$ ) to insure optimal performance.

Over the years, a considerable amount of historical performance data has been accumulated and cataloged for this particular arc-heater, and the resulting database can be used to project performance characteristics at representative MAPX test conditions. Projected variation in electric-to-thermal conversion efficiency with applied electrical power, for instance, is shown in Fig. 4 along with some recently acquired experimental data. These experimental efficiencies were inferred from

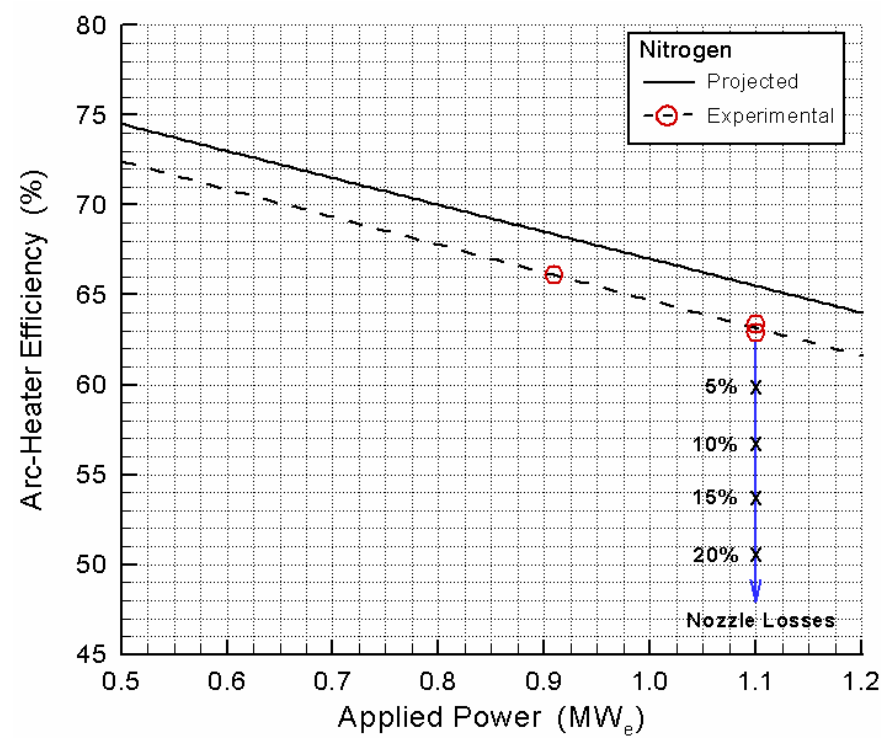

Figure 4. Electric-to-thermal conversion efficiency with assumed nozzle cooling losses.

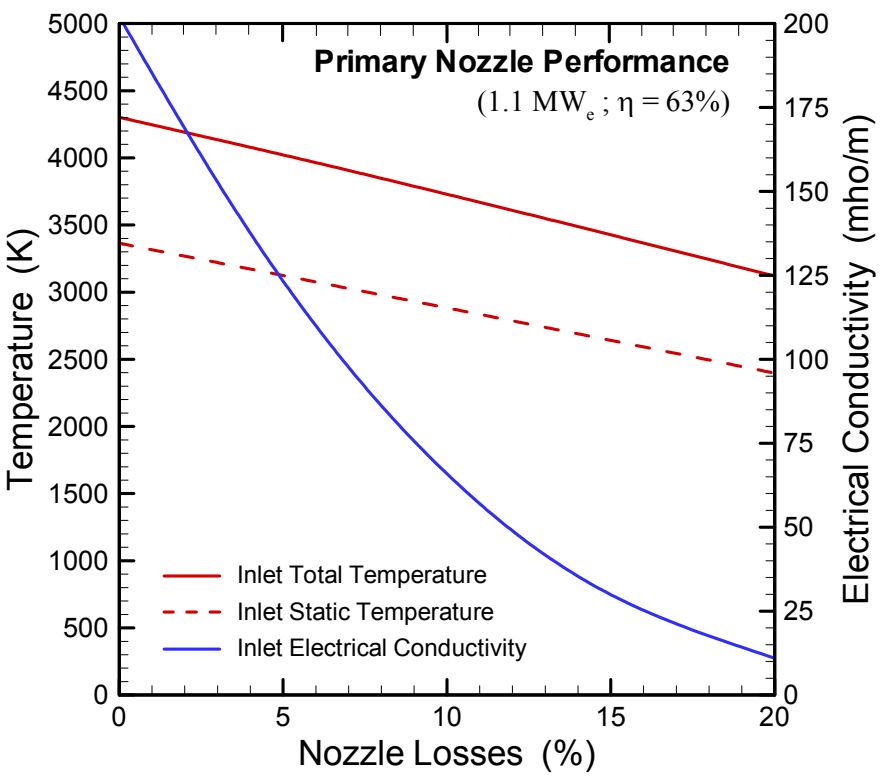

Figure 5. Primary nozzle performance characteristics. 
calorimeter measurements obtained during high flow rate nitrogen runs using an uncooled graphite nozzle with a $5 / 8$-inch $\varnothing$ throat. In general, the projected efficiencies were within one to two percentage points of the experimentally observed values over the examined power range.

Preliminary analysis, assuming an applied electrical power of $1.1 \mathrm{MW}_{\mathrm{e}}$ and nozzle losses of no more than $20 \%$ of the available total enthalpy, indicated that satisfactory conditions could be achieved with $130 \mathrm{~g} / \mathrm{s}$ of nitrogen and $1.5 \% \mathrm{NaK}$ (by weight) using a $0.567 \times 0.567 \mathrm{in}^{2}$ throat with an area expansion ratio of $\mathrm{A} / \mathrm{A}^{*}=1.142297$. The $20 \%$ nozzle heat loss limit was derived from practical experience with water cooled copper nozzles in high-temperature combustors. The primary nozzle performance characteristics were estimated using a modified version of the NASA CEA code, which incorporates a method for computing plasma electrical transport properties. At the $1.1 \mathrm{MW}_{\mathrm{e}}$ operating design point, the arc-heater electric-to-thermal conversion efficiency was experimentally determined to be $\approx 63 \%$, and we project an equilibrium total temperature of $3302 \mathrm{~K}$ at the primary nozzle entrance. Anticipated thermodynamic/electrical conditions at the accelerator entrance are summarized in Fig. 5 as a function of actual primary nozzle performance. These chemical equilibrium calculations indicate that acceptable accelerator inlet conditions can be attained even for the worst case performance scenario. In this performance limiting situation, the inlet static temperature and electrical conductivity are $2397 \mathrm{~K}$ and $11 \mathrm{~S} / \mathrm{m}$, respectively.

\section{B. MHD Accelerator Channel}

\section{Electrical Loading Configuration}

Alternative configurations for linear MHD accelerator channel are depicted in Fig. 6 where the optimal MHD accelerator configuration is determined by the ultimate application needs. From a performance standpoint, the Hall configuration (Fig. 6a) is more effective for low-density flows whereas the Faraday configuration (Fig. 6b), with segmentation to neutralize the Hall current, is superior for high-density flows. The major drawback of the Faraday configuration, however, is the separate power conditioning required for each electrode pair which leads to a complex and expensive system. In many cases, particularly flight applications, multi-terminal loading is not practical.

Alternative two-terminal loading schemes have been proposed to avoid the multi-terminal complications while attempting to reap the major benefit associated with the Faraday configuration (i.e., Hall current neutralization). For example, the standard segmented Faraday channel may be externally diagonalized in a series connected scheme (Fig. 6c), or one could adopt a Diagonal Conducting Wall (DCW) configuration in which slanted window-frame-like

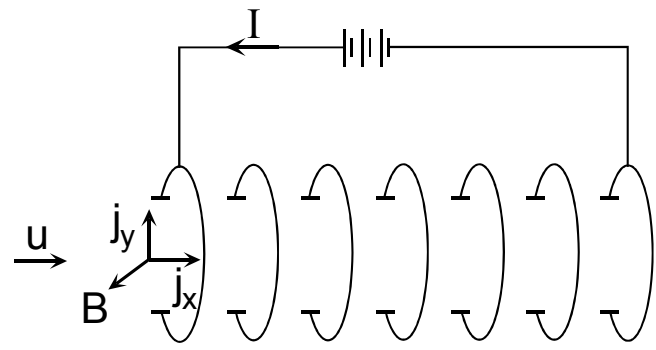

(a) Linear Hall Accelerator

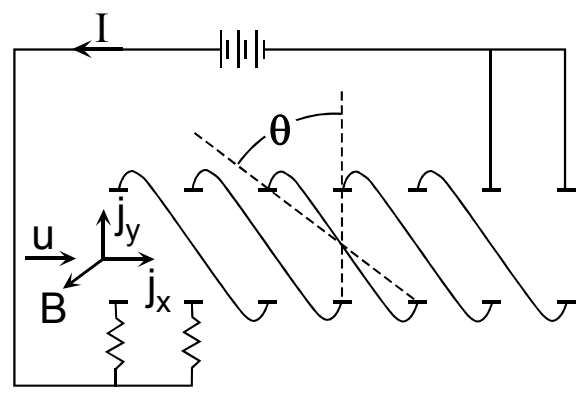

(c) Series Connected Diagonal Accelerator

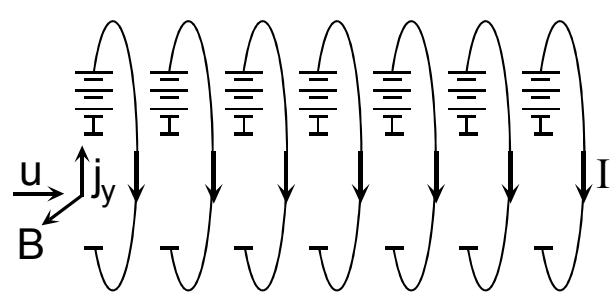

(b) Segmented Faraday Accelerator

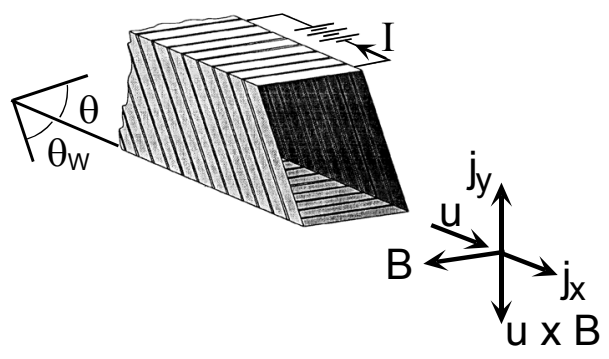

(d) Diagonal Conducting Wall Accelerator

Figure 6. Alternative design configurations for linear MHD accelerator channels. 
electrode elements are stacked with thin insulators to form a complete channel (Fig. 6d). The DCW configuration not only simplifies fabrication and improves strength but provides superior performance to the externally shorted (i.e., series connected) device by allowing current to flow to the sidewalls.

Ultimately, it is the authors' belief that the DCW configuration is the best candidate for flight implementation; however, for reasons of cost and flexibility (e.g., effective wall angle adjustability), MAPX is based on an externally diagonalized series connected configuration. The defining constraint for family of devices is the condition

$$
\frac{E_{y}}{E_{x}}=\tan \theta=\varphi
$$

where $E_{y}$ is the transverse electric field, $E_{x}$ is the axial electric field, $\theta$ is the diagonalization or wall

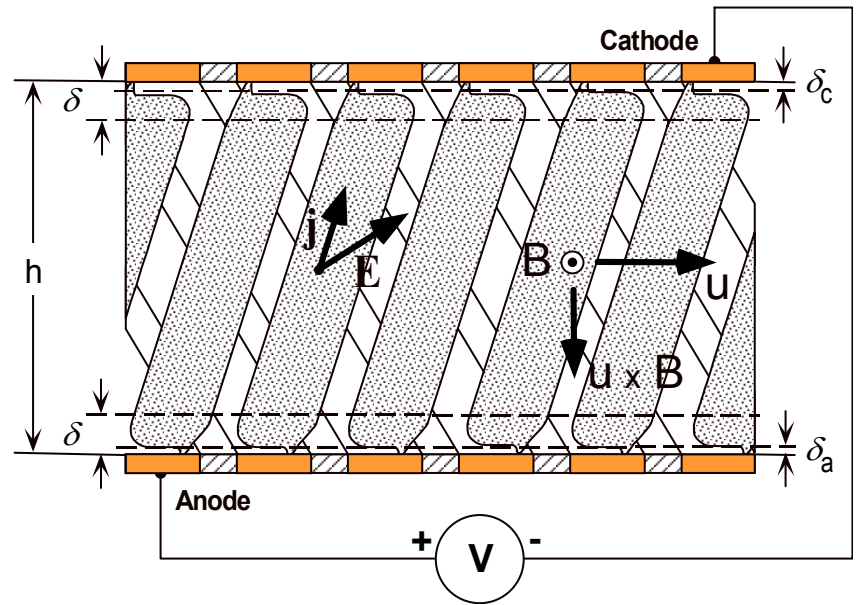

Figure 7. Current transport, field vector orientation, and boundary layer structure in a diagonally connected MHD accelerator channel.

angle, and $\varphi$ is the electric field direction. Thus, diagonal shorting causes the equipotential line to run parallel to the diagonalization angle and aligns the net electric field perpendicular to the diagonal link. The diagonal linkage and resulting field vector orientations are illustrated in Fig. 7. The total current $I$ in the diagonal device is

$$
I=\mathbf{j} \cdot \mathbf{n} \mathbf{A}_{f}=\left(j_{x}+\varphi j_{y}\right) A
$$

where $A_{f}$ is the slant area enclosed by a diagonal link and $\mathbf{n}$ is the normal vector to $A_{f}$.

In all cases, the current density and electric field intensity are related through the generalized Ohm's law

$$
\mathbf{j}=\sigma\left(\mathbf{E}+\mathbf{u} \times \mathbf{B}+\mathbf{E}_{d}\right)-(\beta / B)(\mathbf{j} \times \mathbf{B})
$$

where $\mathbf{j}$ is the current density, $\mathbf{E}$ is the electric field, $\mathbf{u}$ is the streamwise velocity, $\mathbf{B}$ is the magnetic field strength, $\mathbf{E}_{\mathrm{d}}$ $=\mathrm{V}_{\mathrm{d}} / \mathrm{h}$ is the electric field associated with the boundary layer voltage drop, and $\beta$ is the Hall parameter.

Combining Eqs. (1)-(3) yields a set of equations governing diagonally connected accelerator operation in terms of the applied current $I$

$$
\begin{aligned}
& j_{x}=\frac{(1-\beta \varphi) I+A \sigma u B(1+\Delta) \varphi}{A\left(1+\varphi^{2}\right)} \\
& j_{y}=\frac{(\varphi+\beta) I-A \sigma u B(1+\Delta)}{A\left(1+\varphi^{2}\right)} \\
& E_{x}=\frac{\left(1+\beta^{2}\right) I-A \sigma u B(1+\Delta)(\beta-\varphi)}{\sigma A\left(1+\varphi^{2}\right)} \\
& E_{y}=\varphi E_{x}
\end{aligned}
$$

where $\Delta=\mathrm{V}_{\mathrm{d}} / \mathrm{uBh}$ is the dimensionless effective voltage drop associated with cold wall boundary layer effects. The reader may consult original sources for an in-depth discussion of MHD accelerator performance theory. ${ }^{[2]}$

\section{Engineering Performance Model}

Numerous investigations have clearly established that MHD channel flows are subject to significant threedimensional effects. Thus, averaging the governing MHD equations (magnetic Reynolds number $<<1$ ) to obtain a quasi-one-dimensional engineering model requires the adoption of major simplifying assumptions. Nevertheless, many of these assumptions including wall friction, wall heat flux, and near-electrode voltage drops can be accounted for through the introduction of appropriate physical wall functions for the boundary layer.

Performance analysis of the MAPX accelerator was carried out using a legacy code based on one such approach. This engineering code was initially developed within the Energy Conversion Division at the University of Tennessee Space Institute in support of the Department of Energy MHD Commercial Power Program. Over the years, the code 
was evolved and expanded to encompass a range of generator and accelerator loading configurations. In most respects, the development is similar to that described for other non-perfect-gas quasi-one-dimensional analyses; the principle idiosyncrasies being associated with the physical sub-modeling.

The code solves the governing internal duct flow equations for conservation of mass, momentum, and energy together with the equation of state and boundary layer wall functions using a fourth order Runge-Kutta numerical integration scheme. It uses a real-gas equation of state and assumes local thermodynamic equilibrium as predicted by the NASA CEA code with appropriate modifications for computing electrical transport properties.

\section{Design \& Performance Analysis}

Analysis of the MAPX accelerator flow-path was based on performance calculations carried out with a preexisting legacy engineering code. Values for the empirical constants associated with various physical sub-models were established through extensive benchmarking experience.

Heat transfer and frictional wall losses are computed intrinsically in the code and require input of the wall temperature and roughness height. Near-wall electrical losses are also treated intrinsically through integration of the conductivity profile as defined by velocity and thermal boundary layer correlations for fully turbulent flow. This correlation computes the boundary layer growth along the MHD accelerator duct through definition/input of the initial boundary layer height and shear (viscosity as a function of temperature). The velocity and temperature profiles are taken as $1 / \mathrm{n}$ power-law distributions. This approach relies on user specification of the Rosa $\mathrm{G}$ factor to account for plasma non-uniformities and effective voltage drop. A value of $G \approx 2$ is anticipated based on past experience and is therefore utilized for pre-test design and performance analyses purposes.

Detailed design of the accelerator depends, of course, on constraints imposed by the available magnet and power supply equipment. To meet the research goals of this program, a water-cooled 2-tesla electromagnet was acquired from the University of Tennessee Space Institute and refurbished to support general MHD research at NASA MSFC. The specifications for this magnet are summarized in Table I. A new $3000 \mathrm{amp} / 75$ volt DC power supply was acquired to power the magnet, and the entire system has been installed and integrated into the MAPX flow train. A

Table I. Electromagnet Performance Specifications

\begin{tabular}{lc}
\hline Field Strength (tesla) & 2 \\
Air Gap (inches) & 4 \\
Pole Cap Length (inches) & 36 \\
Voltage & 65 \\
Maximum Current (amps) & 2400 \\
Cooling Water (gpm @ 70 psig) & 50 \\
\hline
\end{tabular}

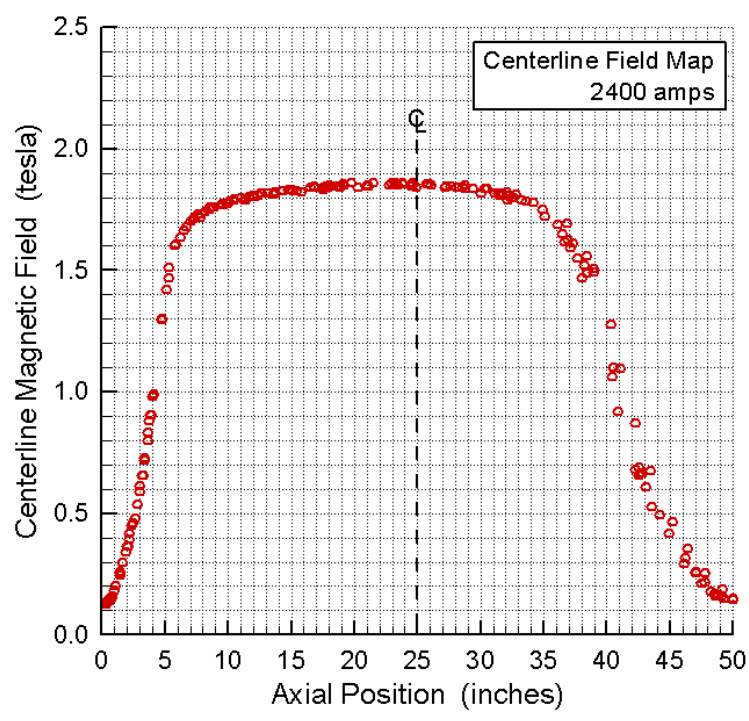

Figure 8. Measured centerline magnetic field strength profiles at 2400 amps applied current. shakedown test of the electromagnet system was conducted and the measured field profile at $2400 \mathrm{amps}$ is shown in Fig. 8. A 2-MW $\mathrm{e}$ high voltage DC power supply was also acquired and installed to power the accelerator. The voltage on the unit is variable to $10-\mathrm{kV}$ and is capable of delivering 300 amps at 6700 volts.

The detailed design process entailed several iterative calculations in an attempt to optimize stagnation pressure rise by varying load current, channel divergence, and channel length. These calculations were carried out utilizing the measured centerline magnetic

Table II. MAPX Accelerator Specifications

\begin{tabular}{lc}
\hline Inlet Height $\times$ Width $\left(\mathrm{cm}^{2}\right)$ & $1.6 \times 1.6$ \\
Channel Divergence $($ degrees $)$ & 1.0 \\
Electrode Width $(\mathrm{cm})$ & 1.0 \\
Insulator Width $(\mathrm{cm})$ & 0.5 \\
Active Length $(\mathrm{cm})$ & 90 \\
Powered Electrodes $\left(\mathrm{N}_{\mathrm{p}}\right)$ & 60 \\
Total Length $(\mathrm{cm})$ & 96 \\
Total Electrodes $(\mathrm{N})$ & 65 \\
Exit Height $\times$ Width $\left(\mathrm{cm}^{2}\right)$ & $3.6 \times 3.6$ \\
Seed $(\%$ NaK) & 1.5 \\
Nitrogen Flow Rate $(\mathrm{g} / \mathrm{s})$ & 130 \\
$\mathrm{~T}_{0, \text { in }}(\mathrm{K})$ & 3120 \\
$\mathrm{P}_{0, \text { in }}(\mathrm{atm})$ & 8.5 \\
$\mathrm{u}_{\text {in }}(\mathrm{m} / \mathrm{s})$ & 1312 \\
$\sigma_{\text {in }}(\mathrm{S} / \mathrm{m})$ & 25 \\
$\beta_{\text {in }}$ & 0.7 \\
\hline
\end{tabular}


field profile at 2400 amps. The height-to-width aspect ratio was unity at the inlet, and the E-field and B-Field walls were diverged to accommodate boundary layer growth and flow expansion. The resulting physical specifications selected for the accelerator design are summarized in Table II.

Preliminary analysis of axial current neutralized operation indicates that the optimal diagonalization angle is near $\theta \approx-45^{\circ}$. In practice, however, finite segmentation imposes a strict constraint on available linkage angles. Furthermore, the Hall parameter varies significantly with axial position in the device due to changes in temperature and pressure, and the optimal wall angle is not truly constant along the entire length. From a practical perspective, therefore, proper diagonalization comes down to a question of how many electrode offsets to impose per link. Given the finite segmentation characteristics of the MAPX channel, there are two realistic possibilities. In the first case, we may consider a two-electrode offset in which the first top electrode is connected to the second bottom electrode the second top electrode is connected to the third bottom electrode and so on to the end of the channel. In the second case, we may consider a three-electrode offset in which the first top electrode is connected to the third bottom electrode the second top electrode is connected to the fourth bottom electrode and so on to the end of the channel. Due to channel divergence, the first case yields a wall angle varying from $-45^{\circ}$ at the inlet to $-26.1^{\circ}$ at the exit, and the second case yields a wall angle varying from $-62.5^{\circ}$ at the inlet to $-45^{\circ}$ at the exit. Preliminary performance estimates indicated that the three-electrode offset would yield superior performance and it was therefore selected for implementation.

A performance analysis survey was performed for the three-electrode offset configuration using applied current as the variation parameter. To keep the electrode current density within practical limits, the power take-off connections were configured to evenly distribute applied electrical current over the first five electrodes on the front and the last three electrodes on the rear of the channel. Cursory exploratory calculations revealed that acceleration performance, as measured by total pressure rise in the channel, was highly sensitivity to shear. In fact, it was found that large friction losses could actually cause a decrease in total pressure during powered operation. Based on past experience with MHD generators, however, it is anticipated that shear levels will be rather moderate, and detailed analysis calculations were carried out using a moderate value for the wall roughness height in the boundary layer wall function, which generated an effective friction coefficient around 0.0025 .

The results of this performance analysis survey are summarized in Fig. 10, which shows the axial distribution of key parameters for a range of applied current levels. The parameter of critical interest is the total pressure, a direct indicator of acceleration effectiveness. From this point of view, the optimal power level is around 200 amps, which increases the total pressure from $8.5 \mathrm{~atm}$ to $11.1 \mathrm{~atm}$ and generates an exhaust velocity slightly in excess of 3000 $\mathrm{m} / \mathrm{s}$. Applied currents greater than 200 amps tend to enhance Joule dissipation more than the push work and MHD acceleration becomes ineffective. This trend may be deduced from casual inspection of the Lorentz force and Joule dissipation plots. In all cases, note that there is a large spike in Joule dissipation near the front of the channel due to the fact that electrical conductivity is relatively low at the entrance and the transverse current density is rapidly rising in the power take-off region. The sudden spike in Joule dissipation does cause rapid heating of the plasma with accompanying increases in ionization level and electrical conductivity, which helps to some extent. The cumulative electrical input power to the accelerator for the $200 \mathrm{amp}$ condition is $730 \mathrm{~kW}_{\mathrm{e}}$ with a total Joule dissipation of $378 \mathrm{~kW}_{\mathrm{e}}$. An additional $190 \mathrm{~kW}_{\mathrm{e}}$ of input energy is lost due to heat transfer to the wall. Because of gasdynamic expansion, the static pressure falls along the channel while electron mobility increases. Thus, the Hall parameter more than doubles its value within the channel, which gives rise to a substantial end-to-end Hall potential approaching 3900 volts for the $200 \mathrm{amp}$ case.

Based on these results, we selected a baseline operational configuration for the MAPX device based on a threeelectrode offset configuration with an applied current in the range of $150-200$ amps. Because of the strong sensitivity to shear, it may be necessary to reduce the current level if the effective friction coefficient turns out to be 

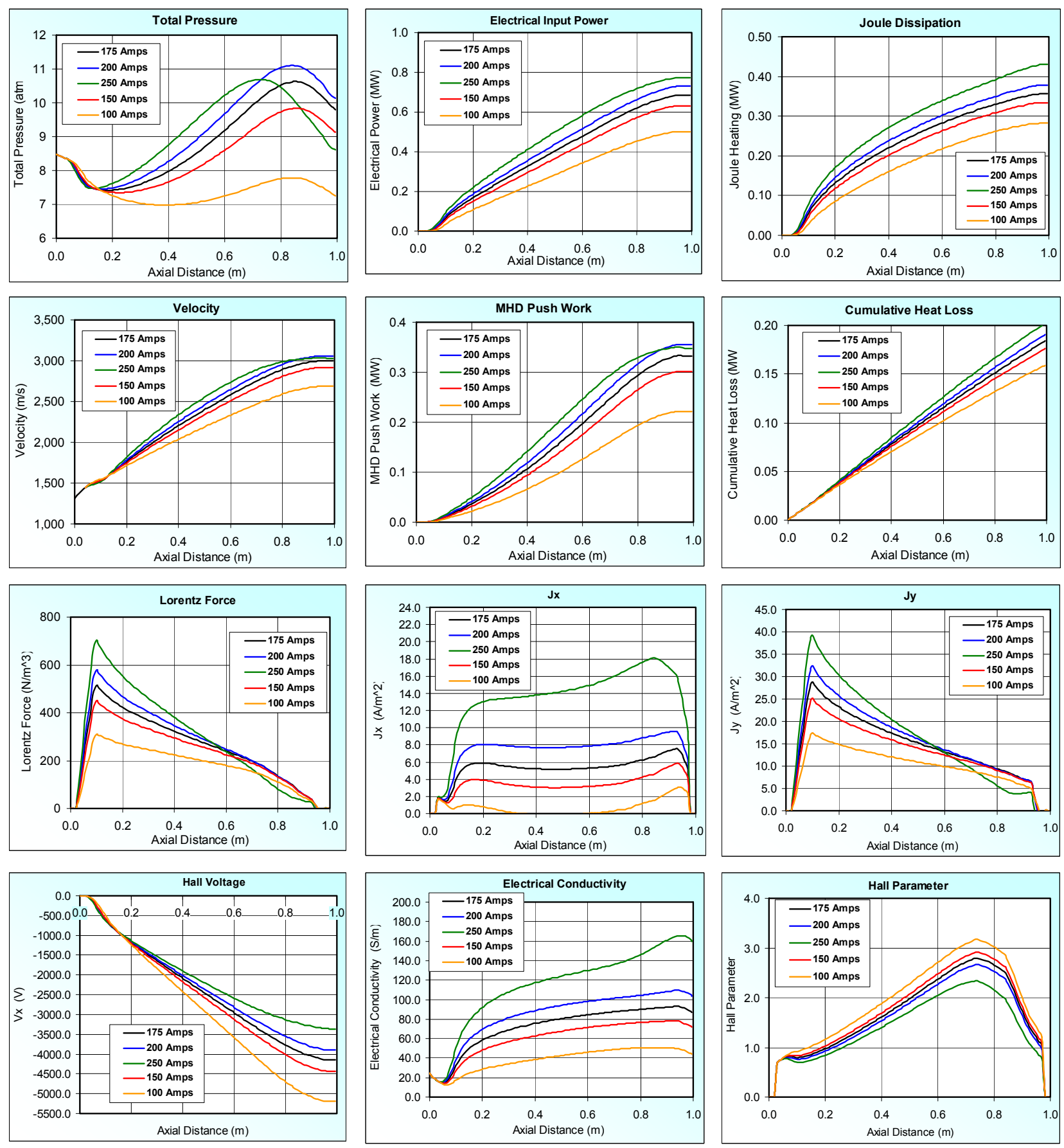

Figure 10. MAPX performance analysis summary with applied current as variation parameter.

greater than anticipated. Based on best current projections for shear, however, we expect an accelerator efficiency approaching 50\% for optimally powered conditions, as shown Fig. 11.

\section{Engineering Design \& Facility Development}

A detailed engineering design was developed using the previously established accelerator specifications and performance analysis estimates as guides. This included the following major components: (1) entrance flowpath hardware associated with the arc-heater interface, NaK mixing chamber, and primary nozzle; (2) MHD accelerator channel; (3) secondary nozzle, test section, and ejector pump; and (4) NaK injector system. The results of these 
design, fabrication, and component testing are summarized below, and the current status of experimental hardware assembly and facility development is discussed.

\section{A. Entrance Flowpath}

The purpose of the entrance flowpath hardware is to accept the hot nitrogen gas from the arc-heater, effectively inject/mix $\mathrm{NaK}$ in the post discharge region while maintaining electrical isolation, and accelerate the resulting plasma to the desired supersonic condition for the MHD accelerator channel. Although the entire test times can be limited to no more than a few seconds, the heat load in this region is so high that the hardware must be water-cooled to survive. This leads to conflicting requirements in that nozzle losses must be kept to a minimum in order to preserve total enthalpy.

The resulting solution to this challenging design problem is illustrated in an exploded schematic of the entrance flowpath hardware assembly in Fig. 12. Here, electrical isolation and circular-to-square cross-sectional area transition are provided by a machinable ceramic insert within a G-11 phenolic casing. This feeds into a water-cooled copper seed injection/mixing chamber which, in turn, is connected to a water-cooled copper flow acceleration nozzle. All of these components have been fabricated and validation testing of the entrance flowpath assembly was conducted during several highpower arc-heater runs, as shown in Fig. 13.

\section{B. MHD Accelerator Channel}

Design of any MHD device poses significant engineering challenges, but the problems are even more severe with an MHD accelerator in comparison to an MHD generator because the stagnation enthalpy becomes several times larger as the flow is accelerated and because the sustained current densities must be substantially higher to obtain the desired performance. Thus, the accelerator environment is more energetically stressed due to increased thermal loading and erosive effects.

This difficulty is amplified by the so called "velocity overshoot" phenomena. The increased stagnation temperature associated with accelerators yields high recovery temperatures and tends to drive the maximum temperature down into the boundary layer. The action of Joule heating in the concentrated current regions near the electrode elevates the boundary layer temperature even further. As a result, the boundary later becomes more highly conductive than the core flow, and the low density regions near the walls is Lorentz accelerated to a velocity higher than the core flow.

Electrical breakdown and development of microarcs at the electrode surface can also lead to major difficulties. Because the characteristic current carried by

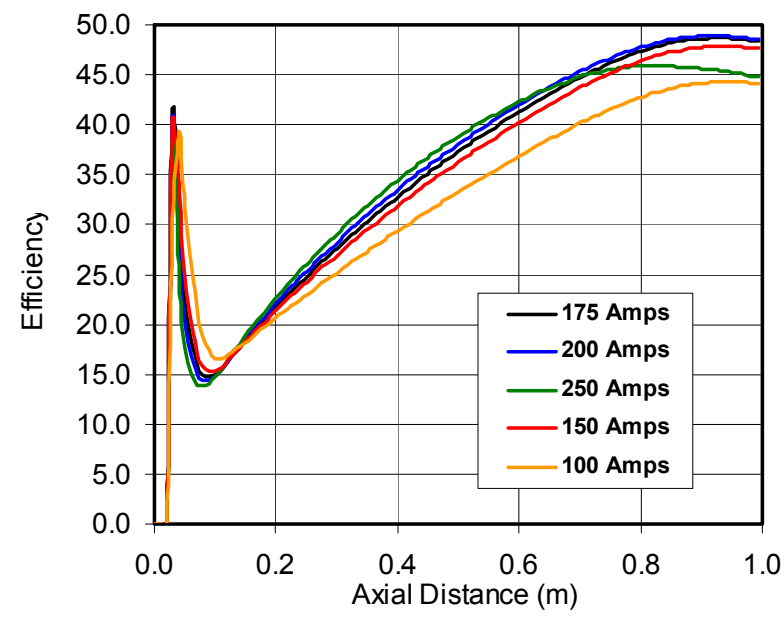

Figure 11. Estimated accelerator efficiency with applied current as variation parameter.

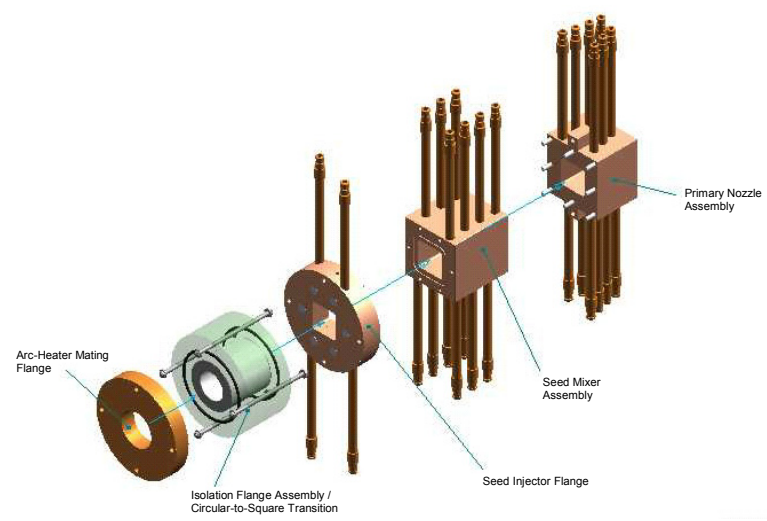

Figure 12. Schematic of MAPX entrance flowpath hardware assembly.

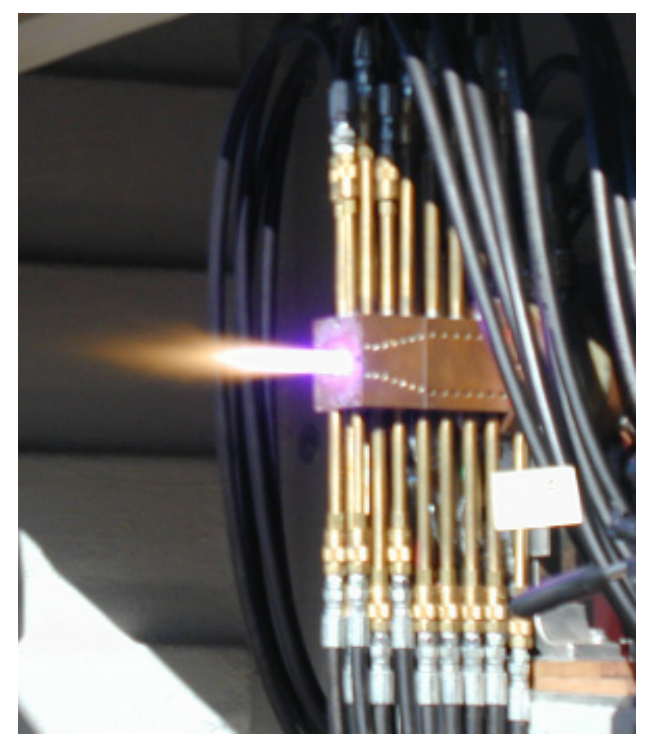

Figure 13. Photograph of MAPX entrance flowpath assembly during high-power arc-heater run with $\mathbf{N}_{2}$. 
an arc is limited (5 to $10 \mathrm{amps}$ ), the number of microarcs formed tends to increase in proportion to the electrode current. Consequently, erosive effects are enhanced and one must be further concerned about the propagation of microarcs downstream and the shorting of electrodes.

In this severe thermal environment, designers typically rely on water-cooled copper alloy electrodes and boron nitride insulators. Insulators formed by sputtering beryllium oxide onto a cooled metal structure are also common since they are known to provide good performance and durability. The principal constraints on mechanical design are related to magnet bore size and Lorentz force loading on the wiring harness.

Because short run times $(\approx 1 \mathrm{sec})$ were acceptable, it was decided to construct the MAPX accelerator as an expendable heat sink device. The goal was to achieve a design that was simple and inexpensive to build yet durable enough to support several test runs before requiring refurbishment. The resulting construction detail is illustrated in the channel cross-section shown in Fig. 14. The basic concept is a channel lined with refractory materials, alumina for the insulating sidewalls and graphite for the electrode walls. These refractory materials are encased in a G-11 phenolic fiberglass reinforced box structure, which seals the duct and provides structural support. The principal thermal constraint for this design approach is an upper limit of $350^{\circ} \mathrm{F}$ for the $\mathrm{G}-11$ material. If the service temperature of the G-11 material is exceeded the material will soften and is subject to the formation of gas voids and delamination.

The channel inner bore dictates an insulating wall thickness of less than one inch. A wall construction comprised of 1/2-inch alumina and 3/8-inch thick G-11 was therefore selected. The alumina has a low value of thermal conductivity and, upon exposure to the hot plasma stream, will experience a rapid rise in surface temperature. As the surface temperature rises, the heat transfer to the wall decreases. The heat transferred to the surface during a test run will be trapped in the material when the run is terminated. Even though the conductivity of the material is low, the trapped heat will eventually dissipate throughout the material. Therefore, the back-face temperature, which is in contact with the G-11 outer structure, will continue to rise until it peaks three to five minutes following completion of a test run.

The use of a cooling purge through the channel before and after an accelerator firing has been implemented into the design with gas injector ports designed into the upstream flange. However, this purge will have only a limited cooling effect. Although heat transfer will decrease along the duct, the thickness of the alumina blocks is held constant along the total length of the sidewalls for simplicity of constructional maintenance.

In general, the electrode walls will be exposed to the same thermal flux as the insulator walls. There are no geometric constraints on the height of the electrodes, but the same temperature limitation applies at the interface between the electrode and G-11. Because the graphite has different properties than the alumina, principally a higher thermal conductivity, it should be much thicker than the alumina. On the other hand, it should not be overly thick, as this offers no advantage. For our design, the soak out temperature was required to be less than that of the $1 / 2$-inch thick alumina sidewall at the same heating condition.

The graphite is also expected to erode in the oxygen carrying plasma and form gaseous carbon dioxide and carbon monoxide. While this chemical erosion is an exothermic reaction, it is anticipated that the heat transfer will not be significantly increased. The cumulative erosion loss will be more pronounced at the entrance but is not expected to be a significant enough to warrant
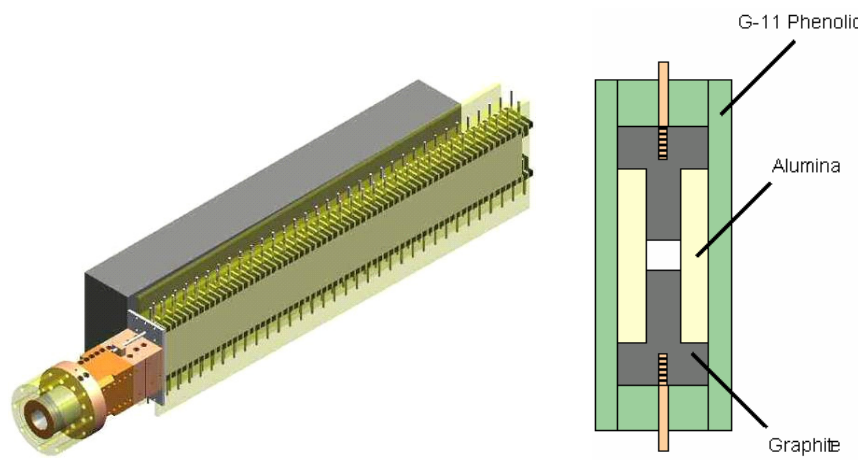

Segmentation Detail

Figure 14. Heat sink MHD accelerator channel design.

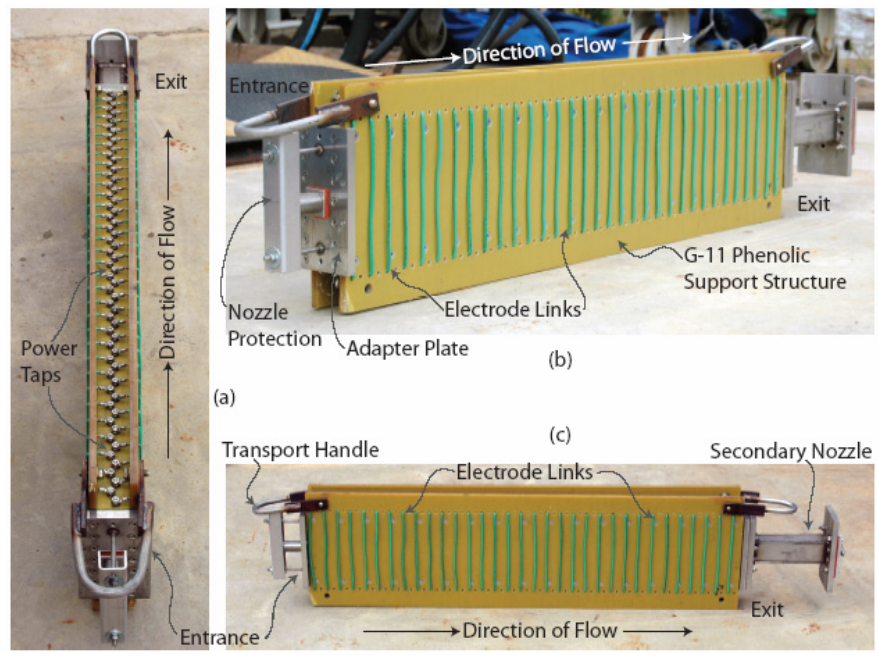

Figure 15. Photograph of Hall connected MHD channel. 
surface coating of the graphite. The electrodes and alumina insulators are keystone shaped pieces that are locked into position by the alumina sidewall blocks. The side-wall pieces are flat slabs of alumina with a lap joint in the axial segmentation. Once installed in the outer G-11 structure the refractory material can be floating, meaning that no rigid attachment to the outer walls is required. Axial motion is prevented by attachment of a channel exit flange. Diagonal shorting of the electrodes is accomplished by running short leads of wire between the external channel assembly and the magnet pole cap. A photograph of the assembled accelerator channel is provided in Fig. 15.

\section{Secondary Nozzle, Test Section, \& Ejector Pump}

Additional exhaust velocity can be obtained by expanding the residual pressure at the end of the accelerator, the ultimate expansion being determined by the backpressure of the evacuation system. In the MAPX design, this is accomplished with a diverging duct. In general, non-equilibrium flow prevails in the secondary nozzle. Nevertheless, actual performance can be predicted reasonably well using a frozen flow model with $\gamma$ dependent on the species concentrations exiting the accelerator since the presence of seed tends to deactivate the vibrational degrees of freedom for nitrogen, which can lead to an increase in velocity and a rise in static temperature at the nozzle exit.

The secondary nozzle for MAPX is designed as an uncooled two-piece unit, which allows the flow train to be separated at a convenient location for maintenance purposes. The first stage section is $20-\mathrm{cm}$ long with a $0.6^{\circ}$ divergence. Two interchangeable $32.5-\mathrm{cm}$ long secondary stage sections were designed having divergence angles of $1.7^{\circ}$ and $2.5^{\circ}$, respectively. These nozzles consist of carbon steel sheets welded together to form an expanding duct. The secondary nozzles were sized to exhaust into a large test section, which is evacuated by a nitrogen driven ejector pump designed to generate a deadhead backpressure less than 1.0 psia. The secondary nozzles, test section, and ejector pump were all designed and fabricated by NASA MSFC. A photograph of the installed test section with attached nitrogen ejector pump is shown in Fig. 16.

To verify ejector performance, various tests were conducted while deadheaded, with cold nitrogen flow, and with hot nitrogen flow at design point condition. The results of these tests are summarized in Fig. 17 which shows the cabin pressure as a function of motive gas total pressure. Maximum pumping capacity occurs when the motive gas total pressure reaches the 780 to 800 psig range. When deadheaded, the ejector pump can hold a steady cabin pressure of $\approx 0.5$ psia. If $130 \mathrm{~g} / \mathrm{s}$ of cold nitrogen flow is introduced through the arc-heater, the cabin pressure is slightly increased to 0.9 psia. When the arc-heater is run at the design point power level of $1.1 \mathrm{MW}_{\mathrm{e}}$ with 130 $\mathrm{g} / \mathrm{sec}$ of nitrogen flow, the ejector is able to maintain a stable cabin pressure of 1.1 psia, which is well within the original facility design specifications.

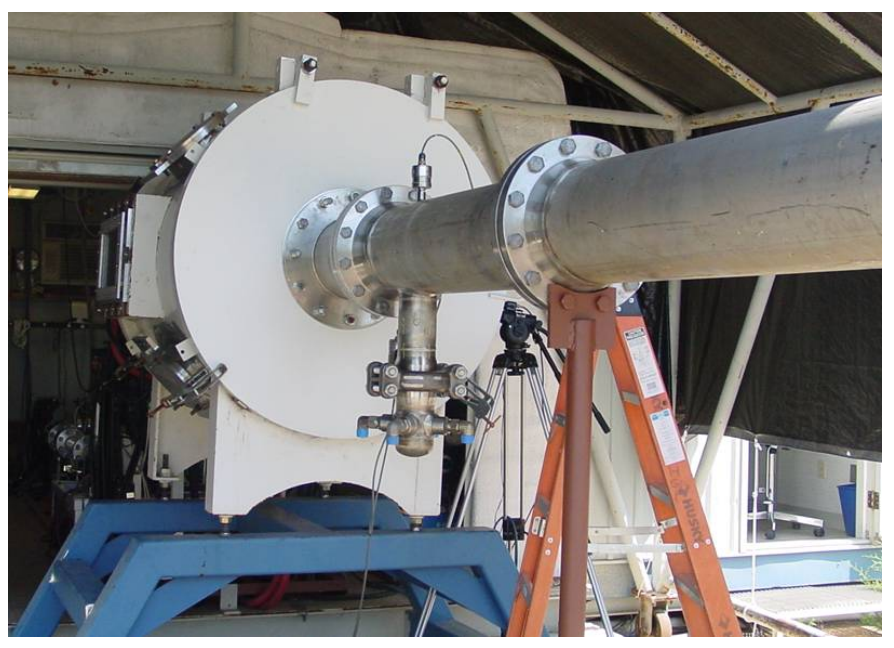

Figure 16. Installed test section and ejector pump.

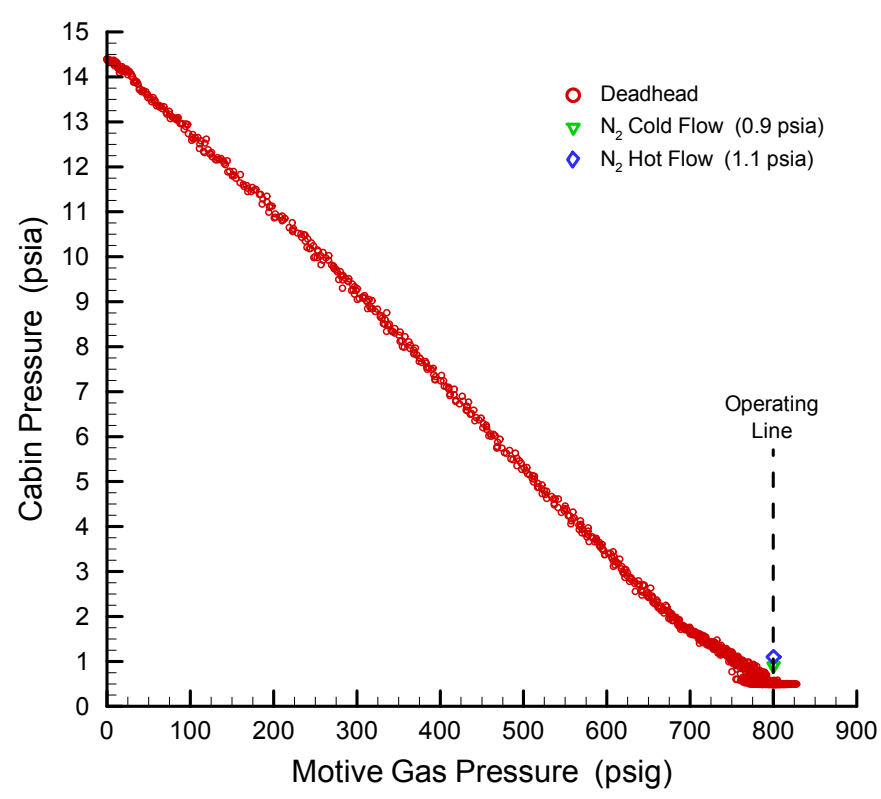

Figure 17. $\mathrm{N}_{2}$ ejector pump performance characteristics. 


\section{NaK Injector System}

Eutectic NaK alloy (78 wt \% K, $22 \mathrm{wt} \% \mathrm{Na}$ ) was selected as the ionization seed because it is liquid at room temperature and may be introduced to the hot process stream using a conventional liquid spray injector. The drawback of this approach is that $\mathrm{NaK}$ reacts explosively with water to form hydrogen, potassium hydroxide, and sodium hydroxide, and extreme precautions must be taken when handling, transferring, and disposing of this potentially dangerous material.

The basic architecture for the $\mathrm{NaK}$ injection system is illustrated in the P\&I diagram shown in Fig. 18. NaK is stored in a small stainless steel reservoir and a SOV fabricated with $\mathrm{NaK}$ compatible materials is used for injection flow control. For simplicity, we employ a coaxial injector design in which $\mathrm{NaK}$ is introduced through the center post and high purity argon flows through the annulus as a non-reactive shroud gas for the purpose of providing atomization action. The coaxial injector is formed by inserting a $0.0625^{\prime \prime} \mathrm{OD} \times$ $0.0225^{\prime \prime} \mathrm{ID} \times 12^{\prime \prime} \mathrm{L}$ stainless steel center tube into a $0.125^{\prime \prime} \mathrm{OD} \times 0.085^{\prime \prime} \mathrm{ID}$ stainless steel shroud tube. The inner tube is maintained in a non-contact centered position by spot welding a spiraled wire on its outer surface. The photograph in Fig. 19 shows the major injector components during the loading procedure in which $\mathrm{NaK}$ is transferred from the storage drum to the injector reservoir.

The injector was flow calibrated using water, which has a similar viscosity and density, and the mass flow rate is found to be a linear function of $\sqrt{ }(\rho \Delta p))$. The result of the calibration for three different injector tubes is shown in Fig. 20, and demonstrates good repeatability and insignificant variability between tubes. Thus, the resulting linear trendline could be used as dependable calibration curve for predicting $\mathrm{NaK}$ injection rates.

Verification of $\mathrm{NaK}$ injection system performance was determined from a series of free-jet tests in which the arc-heater was run at design point condition with the MAPX entrance flowpath hardware installed. During these tests, the $\mathrm{NaK}$ injector was activated for a short time interval, and the free-jet plume was interrogated with a polychromatic microwave interferometer $(70 / 90 / 110 \mathrm{GHz})$ and a high speed digital camera. Extracted images of the free-jet plume, with and without $\mathrm{NaK}$ injection, are shown in Fig. 21. From these results we were able to conclude that the injection and mixing processes were effective and that we were obtaining a satisfactory level of plasma ionization. By monitoring the center tube purge gas flow rate after each test we were able to confirm that some slight plugging would occur during each shot. However, these measurements indicated that it would be possible to run at least 3 to 4 times before the plugging became so severe that the injector tube would need to be replaced.

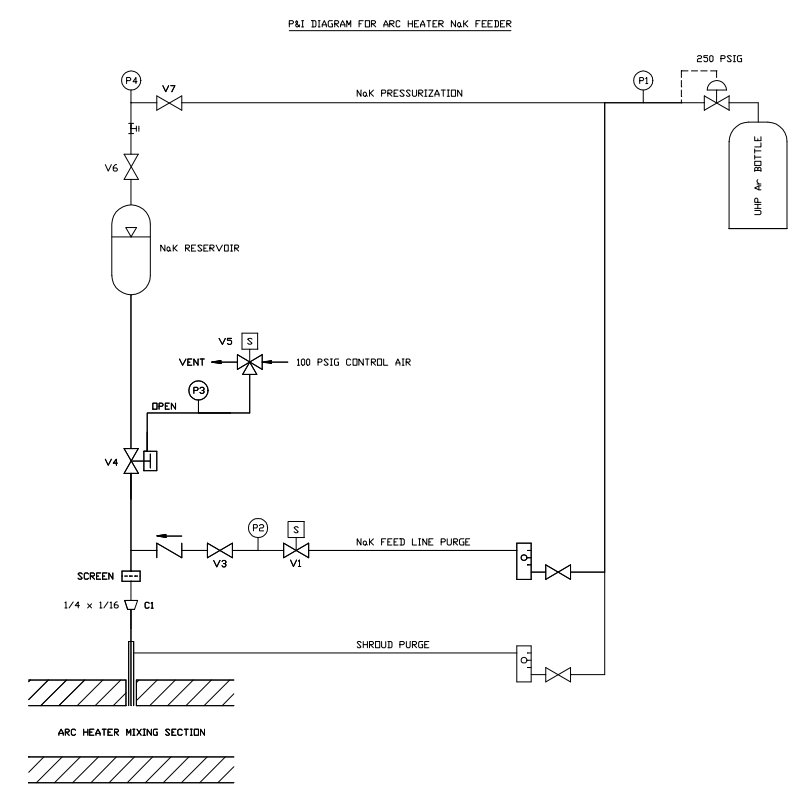

Figure 18. P\&I diagram for NaK injector system.

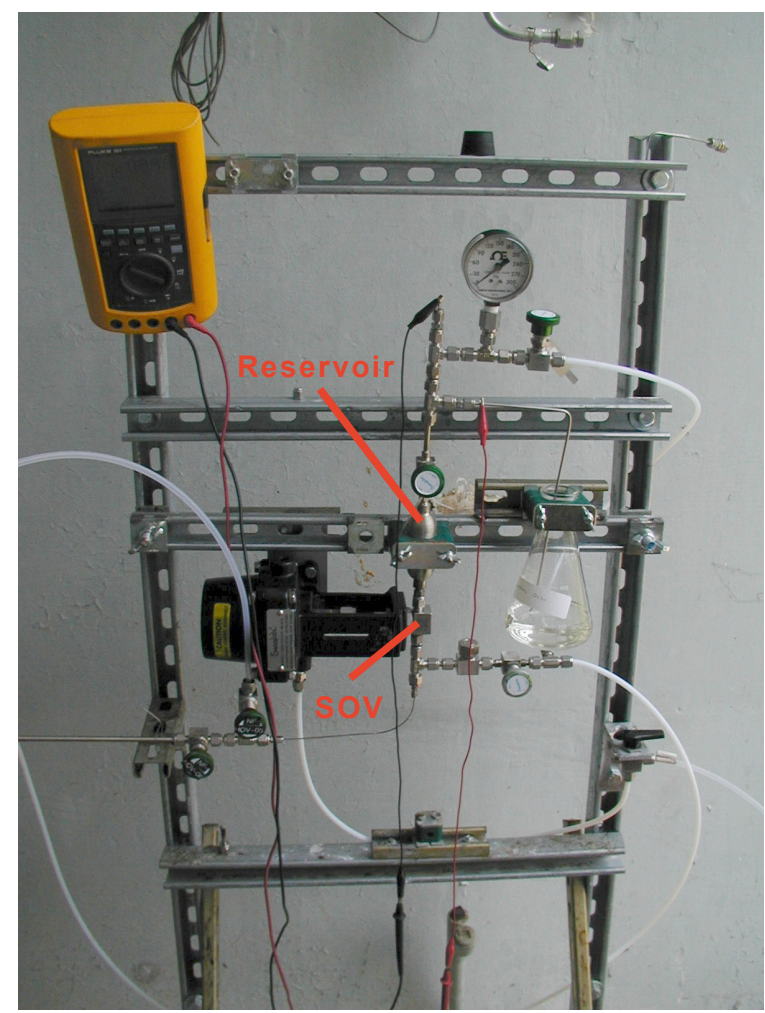

Figure 19. Photograph of NaK injector hardware during loading operations. 


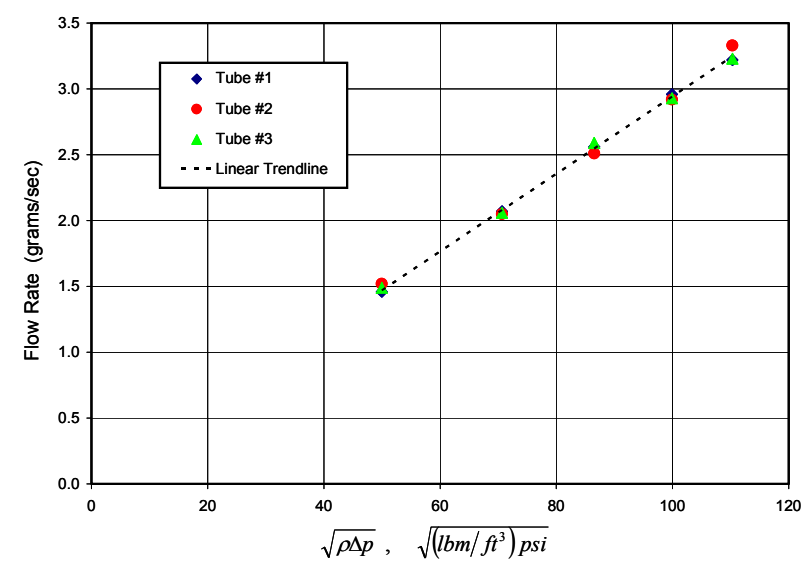

Figure 20. NaK injector calibration curve based on water flow.
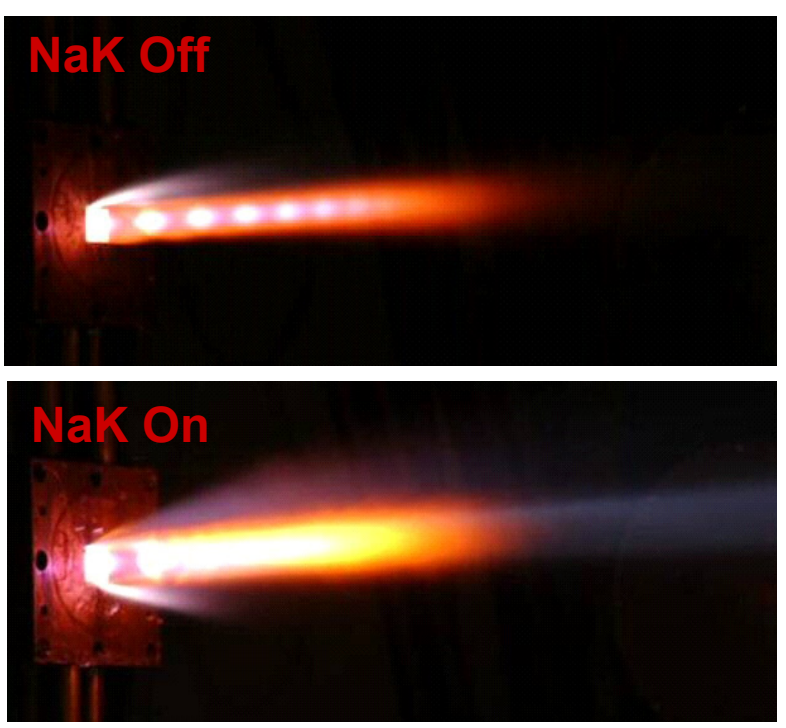

Figure 21. Images extracted from high-speed digital video of free-jet plume with/without NaK

\section{Concluding Remarks}

Despite numerous programmatic setbacks, development of NASA's MHD augmented propulsion experiment is continuing and considerable technical progress has been made in preparation for the proposed technology feasibility tests. Engineering design and fabrication tasks have been completed and all hardware is now on-hand and available for utilization. Component verification testing has been completed, and sub-system performance was found to meet or exceed design specifications. Pre-test performance optimization analyses have been successfully completed, and the accelerator diagonalization configuration and optimal power point have been defined. When optimally powered, we anticipate that the accelerator will generate a total pressure rise of about $3 \mathrm{~atm}$. Due to the small size of the device, however, actual performance will be very sensitive to wall shear, which cannot be predicted with a high degree of confidence. Ultimately, the performance and technical feasibility of the concept must be determined through experiment. Current efforts are directed at experiment assembly and facility integration with initial testing to be undertaken during the latter half of 2007.

\section{Acknowledgments}

Initial funding for the MAPX project was obtained from the Advanced Propulsion Research Project Office under the Advanced Space Transportation Program at NASA Marshall Space Flight Center. Additional sustaining funds were obtained from the NASA MSFC Technology Innovation Program, from Reimbursable Space Act Agreement SAA8-05786 sponsored by General Atomics, and from Reimbursable Space Act Agreement SAA8-05952 sponsored by LyTec LLC.

\section{References}

[1] R. J. Litchford, J. W. Cole, J. T. Lineberry, J. N. Chapman, H. J. Schmidt, and C. W. Lineberry, "Magnetohydrodynamic Augmented Propulsion Experiment: Performance Analysis and Design," AIAA Paper 2002-2184, 33rd Plasmadynamics \& Lasers Conference / 14th International Conference on MHD Power Generation and High Temperature Technologies, May 2002.

[2] R. J. Litchford, "Performance Theory of Diagonal Conducting Wall Magnetohydrodynamic Accelerators," AIAA Journal of Propulsion and Power, Vol. 20, No. 4, July-August 2004, pp. 742-750. 


\title{
Magnetohydrodynamic Augmented Propulsion Experiment
}

\author{
Ron Litchford \\ NASA - Marshall Space Flight Center
}

Japan MHD Society

2008 Annual Technical Meeting

30-31 May 2008, Yamanakako, Japan 


\section{Project Background}

- MHD Augmented Propulsion

- Hybrid thermal-electric propulsion concept

- Seeking increased Isp with high jet power $\quad($ Isp $\approx 800-1000 \mathrm{sec})$

- Improve performance capability and mission reliability - Assured Propulsion

- Dual use technology - MHD Hypersonic Wind Tunnel

- Technical Demonstration/Feasibility R\&D Project

- Initiated by ASTP Advanced Propulsion Research Project Office

- Numerous programmatic setbacks

- TIP project sustaining funds

- Objectives

- Critically examine technical feasibility

- MW-scale experiment

- Arc-heater thermal driver

- Accelerator effectiveness

- Expose important trends \& sensitivities

— Validate performance models

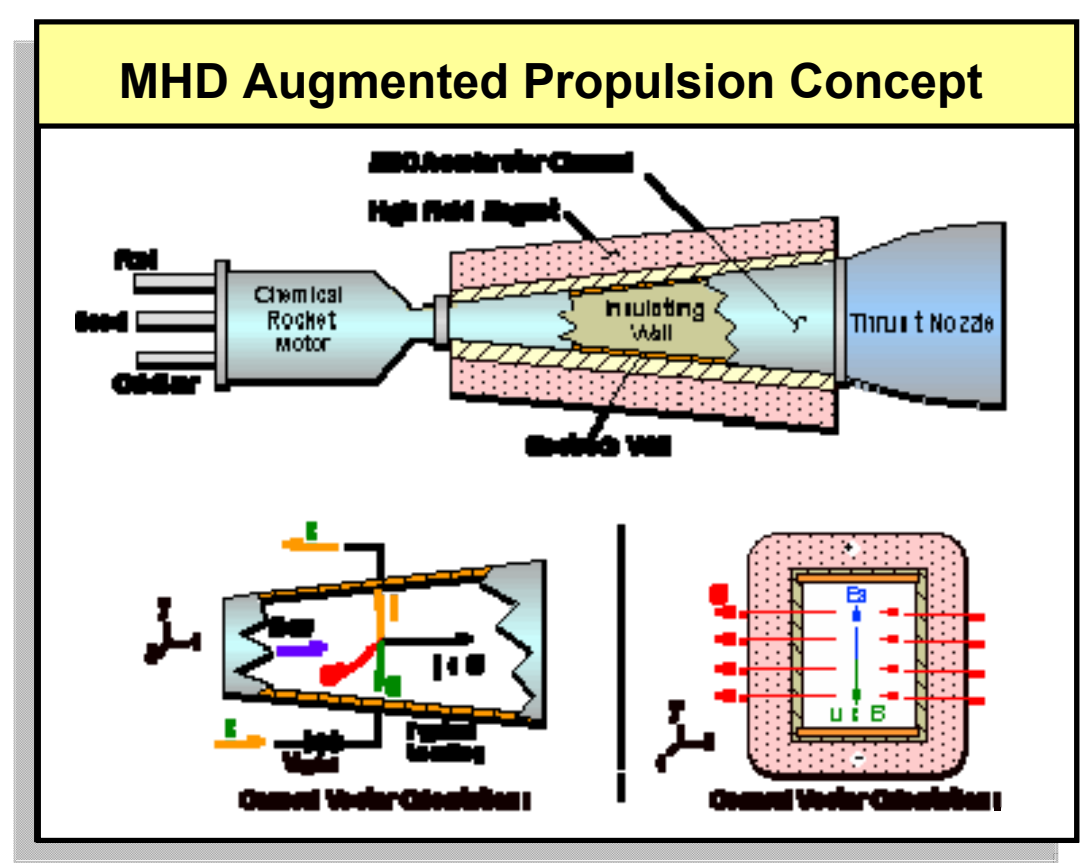




\section{Experiment Description}

Marshall Space Flight Center

\section{- MHD Augmented Propulsion Experiment (MAPX)}

- Experiment development complete (see AIAA-2007-3884)

- Special test equipment

- Design / hardware fabrication

- Component level testing

- Pre-test analyses

- TIP testing - November 2007

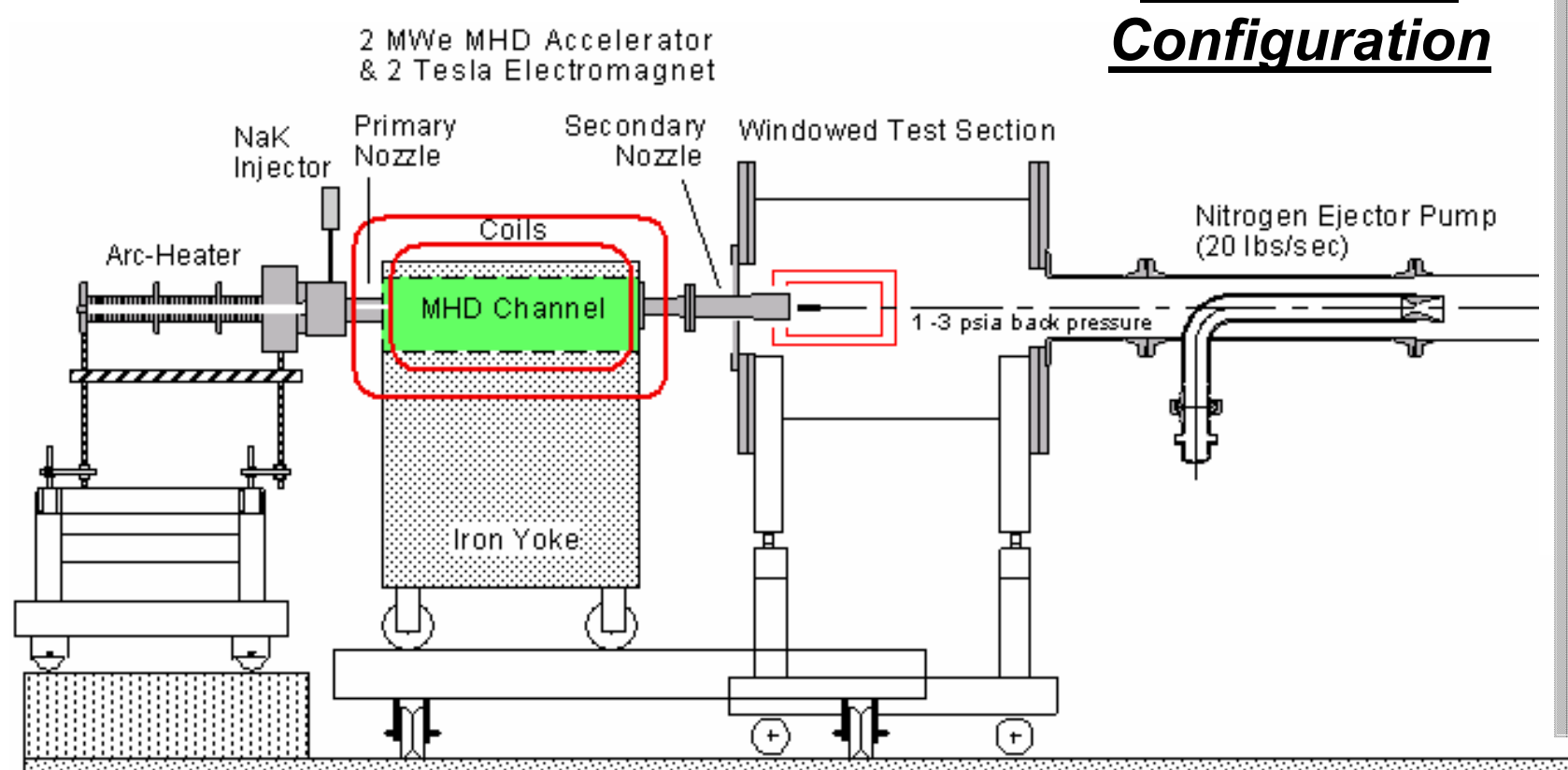

Experiment Configuration

Nitrogen Ejector Pump (20 losisec) ת

\section{Design Attributes}

- Arc-Heater Thermal Source

$-\mathrm{T}_{0} \approx 4000 \mathrm{~K}$

- $\mathrm{P}_{0} \approx 8-10 \mathrm{~atm}$

- Liquid Metal Ionization Seed

- 2\% NaK

- Supersonic Primary Nozzle

- Water Cooled $(M \approx 1.3)$

- 2-MW $\mathbf{M}_{\mathrm{e}}$ MHD Accelerator

- diagonal connected segments

- 2-tesla electromagnet

- Secondary Nozzle

- hypersonic exhaust

- Nitrogen Ejector

- $1-3$ psia backpressure 


\section{MSFC Multi-Gas Arc-Heater}
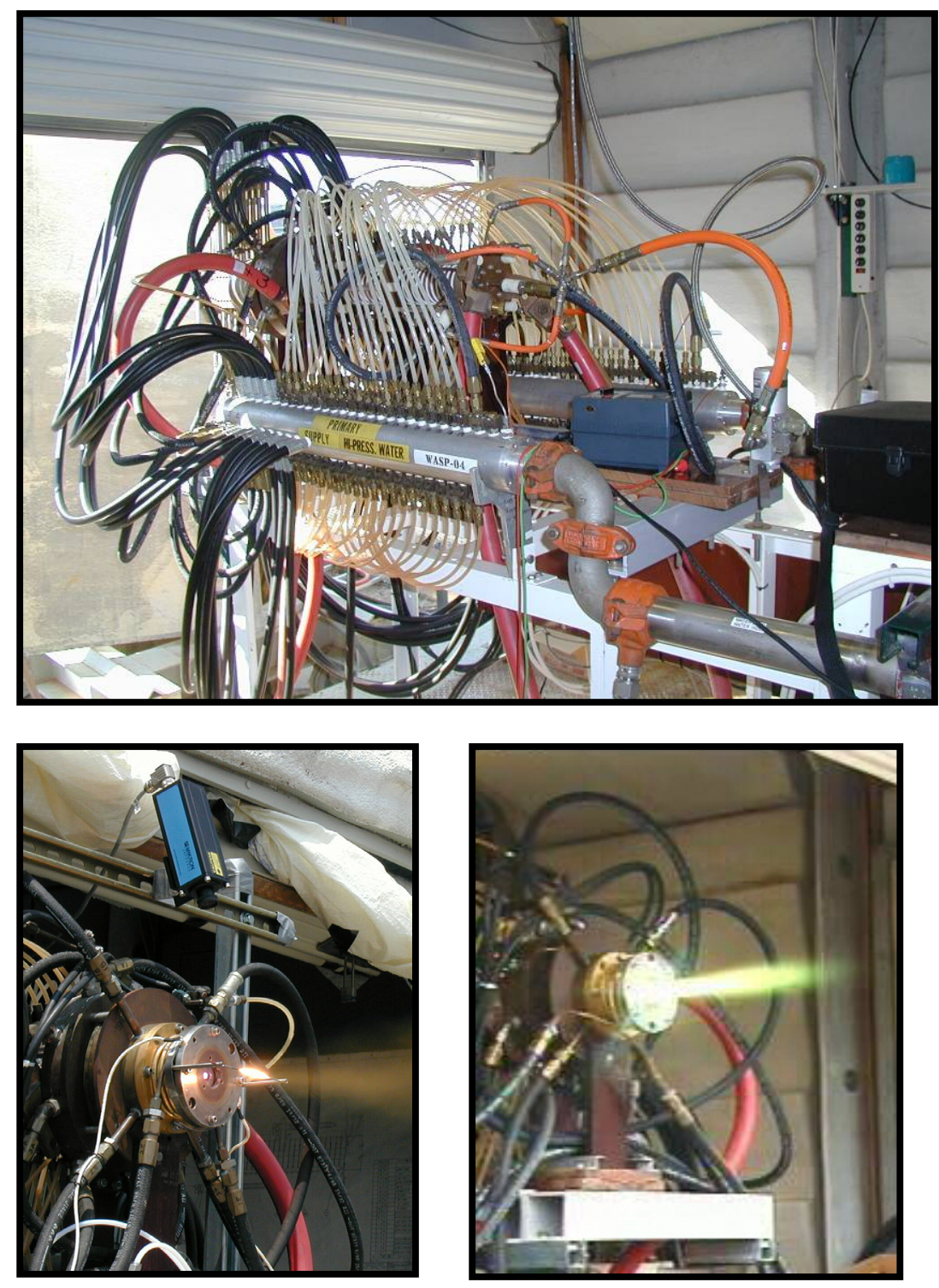

- Heritage

- 1960's Legacy Aerotherm Design

- three decades of operational history

- Large database of experience with system

- established procedures/performance

- Reactivated in East Test Area - METCO

- Type/Classification

- Water-cooled wall-stabilized constricted arc

- Small scale $\left(\sim 1 \mathrm{MW}_{\mathrm{e}}\right.$, nominal)

- Relatively low operational cost

- Utilization

- Hyperthermal Convective Environments

- Ablation / Propulsion Materials R\&D

- Magnetohydrodynamics R\&D

- Nuclear Reactor Materials R\&D 


\section{MSFC Multi-Gas Arc-Heater - System Description}

- Design/Operational Characteristics

- Wall-stabilized constricted arc DC discharge

- Alternating conductor/insulator wafer segmentation

- copper conducting segments / boron nitride insulators

- stacked pack assembly (3-pack configuration shown)

- 1-inch internal bore diameter / 1-meter long

- $0.75 \mathrm{MW}_{\mathrm{e}}$ (continuous) / 1.5 $\mathrm{MW}_{\mathrm{e}}$ (intermittent)

- $50-60 \%$ power conversion efficiency (typical)

— 35 -atm stagnation pressure (maximum)
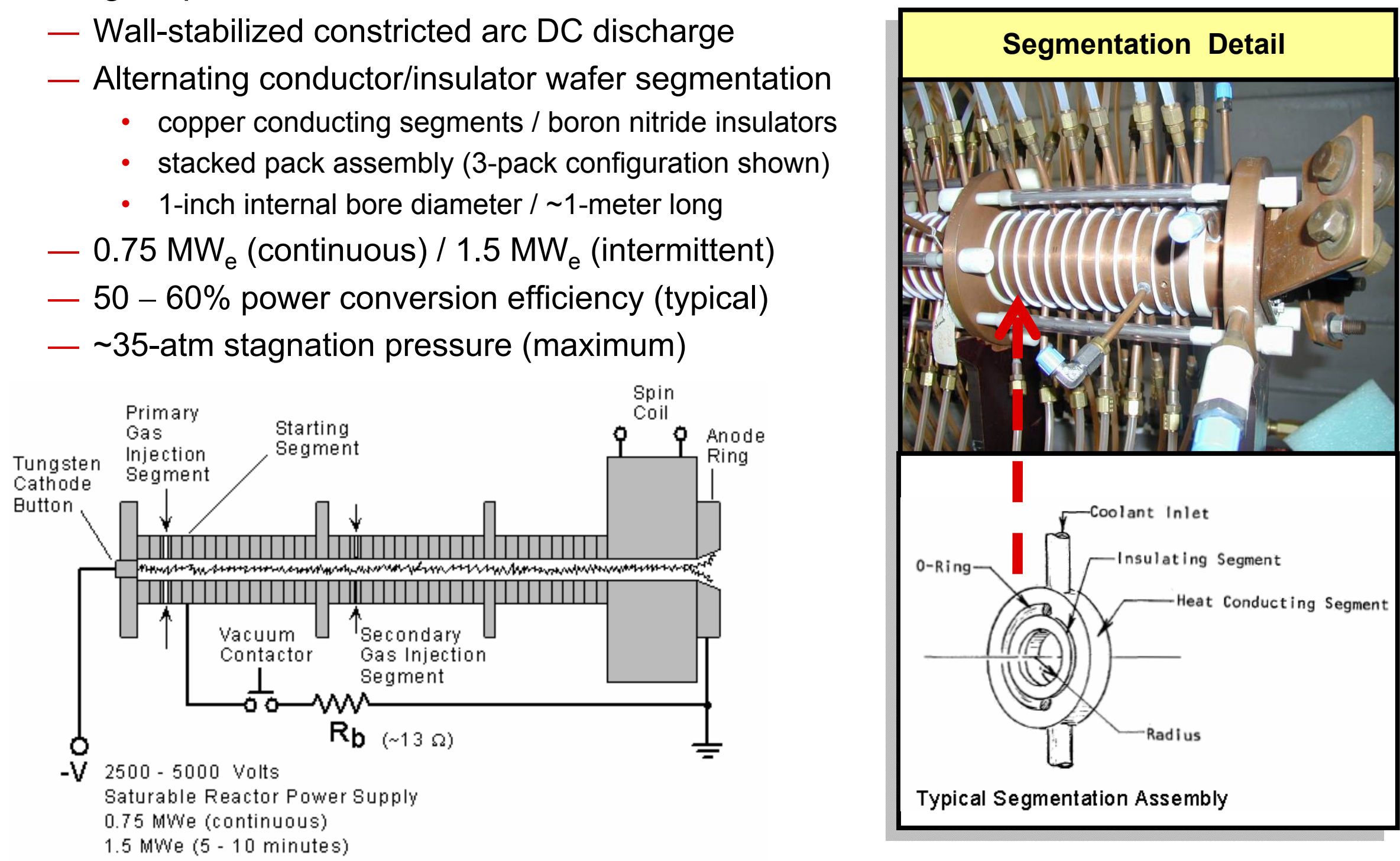


\section{MSFC Multi-Gas Arc-Heater - System Description}

Marshall Space Flight Center

- Water Cooling Loop

- De-ionized water (8000-gal storage)

- Long duration continuous operation

- High pressure/flow pumping capacity

- Calorimeter measurements

- Multi-Gas Capability

- Argon / Nitrogen (existing)

- Expansion ports available

- Combustion gas simulation capability

- Tube trailer connectivity

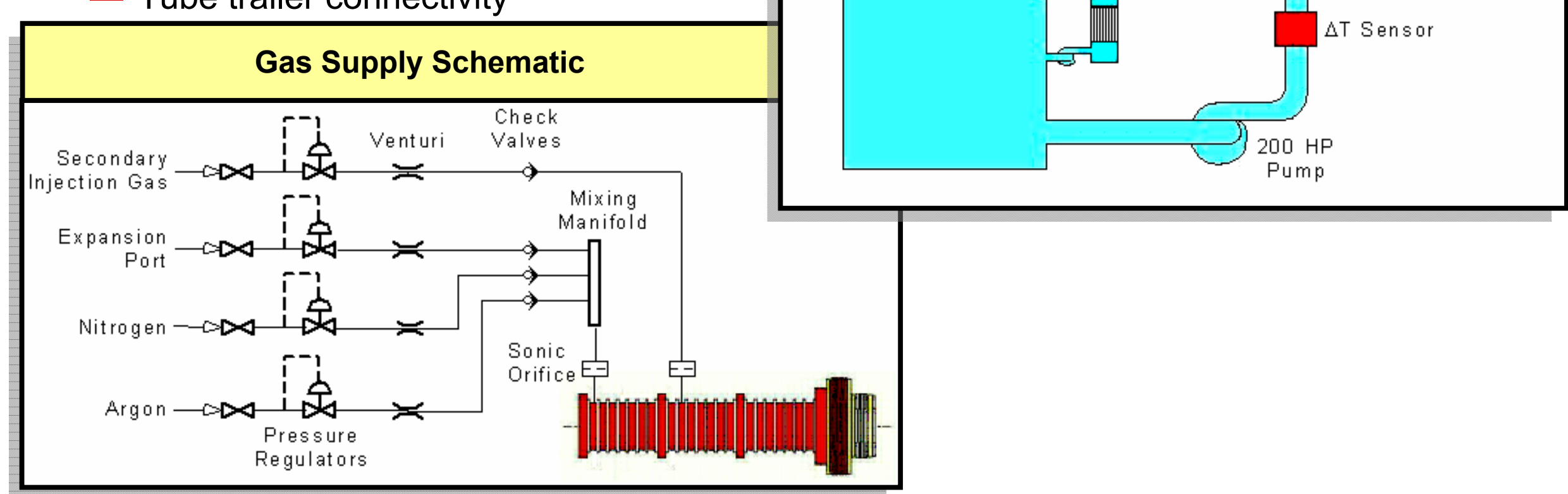




\section{MSFC Multi-Gas Arc-Heater - Facility Layout}

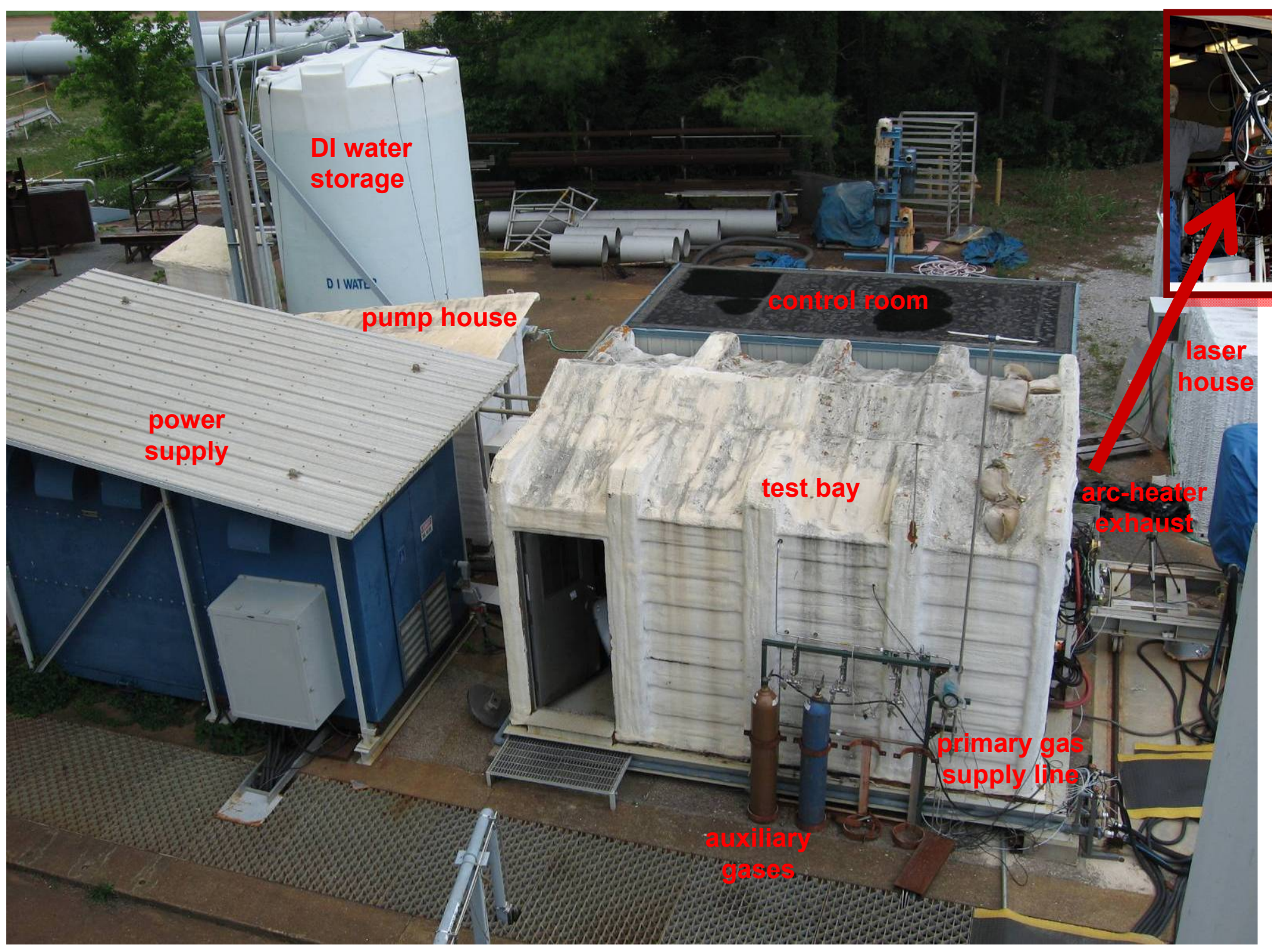




\section{Arc-Heater Performance Characterization Testing}

Marshall Space Flight Center

- Demonstrate High-Power MAPX Operating Point

$-110-130 \mathrm{~g} / \mathrm{s} \mathrm{N}_{2}$

$-\mathrm{T}_{0}>4000 \mathrm{~K}$

$-\mathrm{P}_{0} \approx 8-10 \mathrm{~atm}$

- Minimize test duration ( $3-5$ seconds max)

- Equivalent Nozzle Configuration

- Graphite

$-5 / 8 " \varnothing$ throat

- Principal Testing Accomplishments

- Increased understanding/confidence

- Atmospheric pressure start-up

- Reliable arc formation \& control

- power/flow ramping

- on-point stability

— Design stagnation conditions @ $1.1 \mathrm{MW}_{\mathrm{e}}$

- $\mathrm{T}_{0} \approx 4000 \mathrm{~K}$ (inferred equilibrium value)

- $\mathrm{P}_{0} \approx 9 \mathrm{~atm}$

- acceptable efficiency

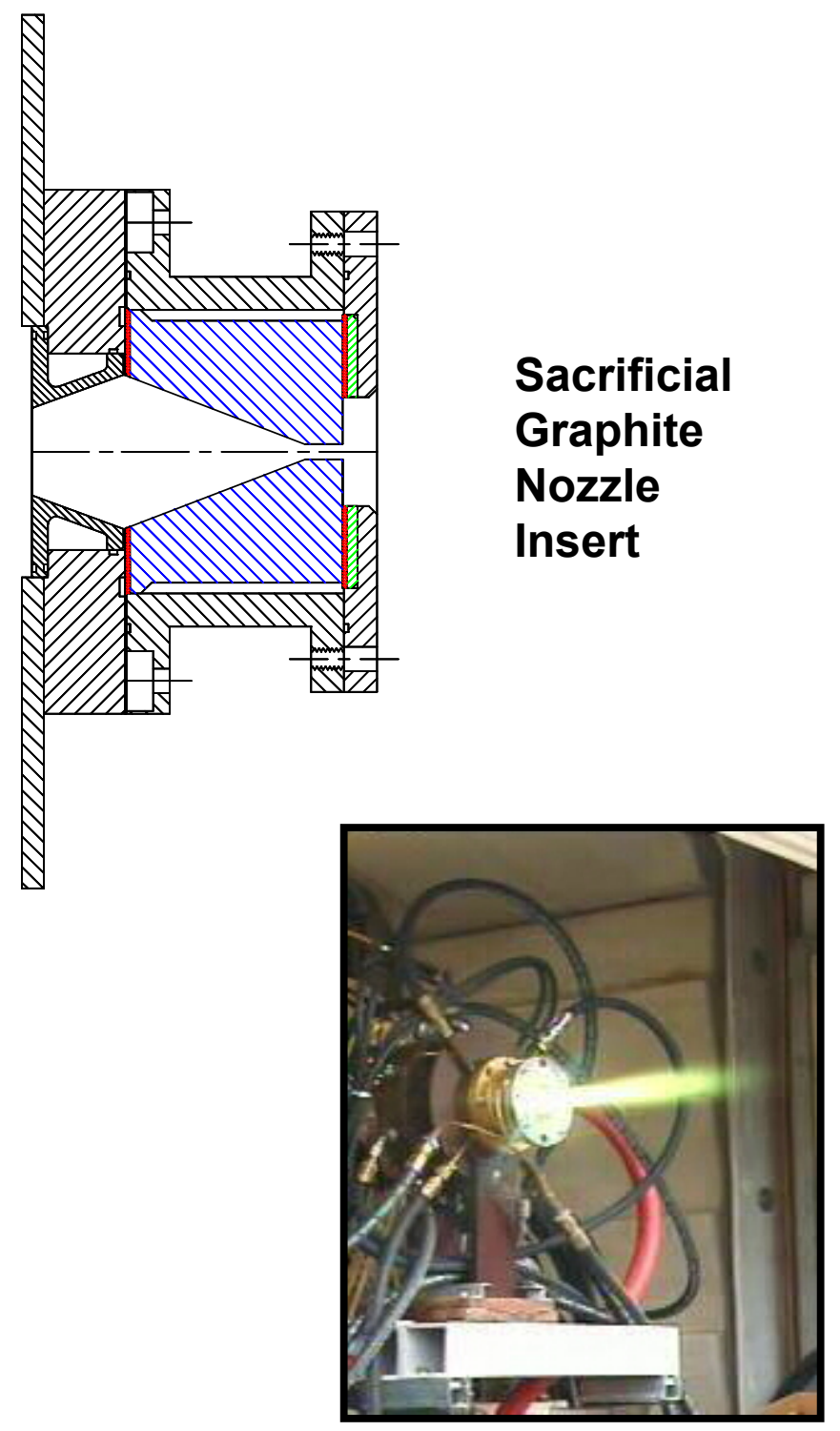




\section{Arc-Heater Efficiency}

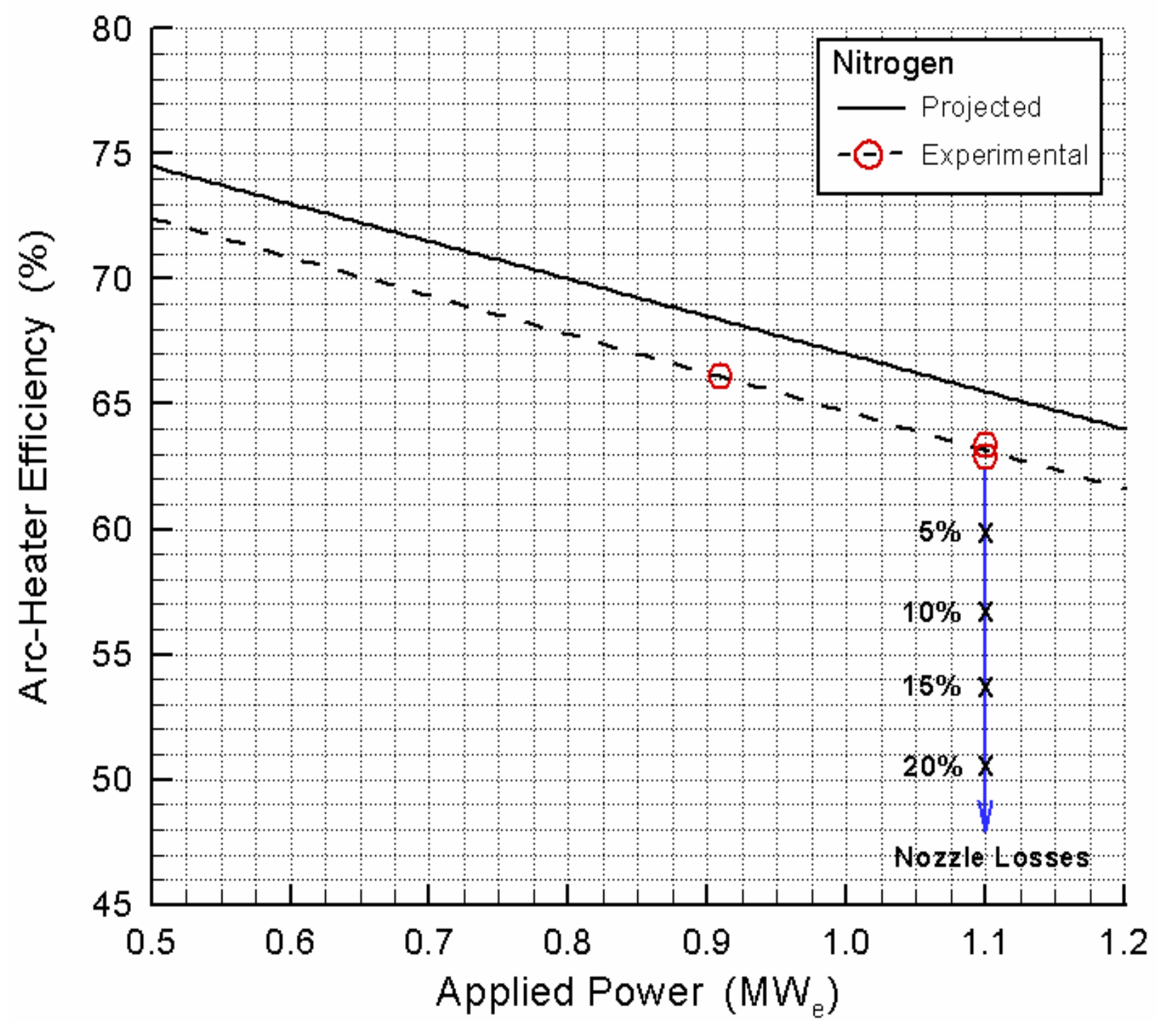




\section{Primary Nozzle Performance Estimates}

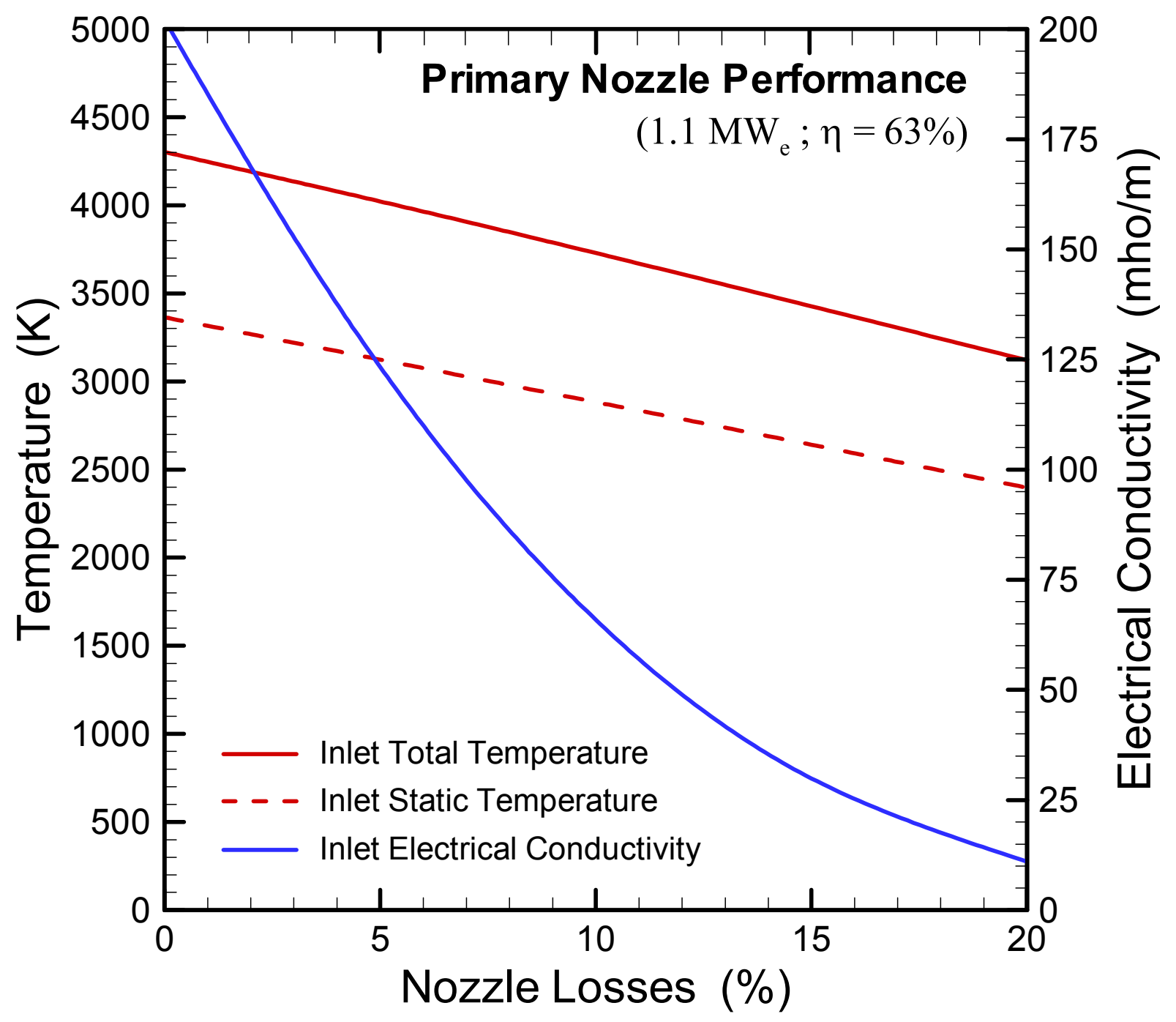




\section{Entrance Flow Path Assembly}

- Design \& Fabrication

- Water-cooled copper

- Arc-heater interface adaptor

- Isolation flange

- Ceramic insert / G-11 phenolic casing

- Round-to-square flow path transition

- Seed injection/mixing chamber

- Primary nozzle

- $0.567^{\prime \prime} \times 0.567^{\prime \prime}$ throat

$-\mathrm{A} / \mathrm{A}^{*}=1.1423$

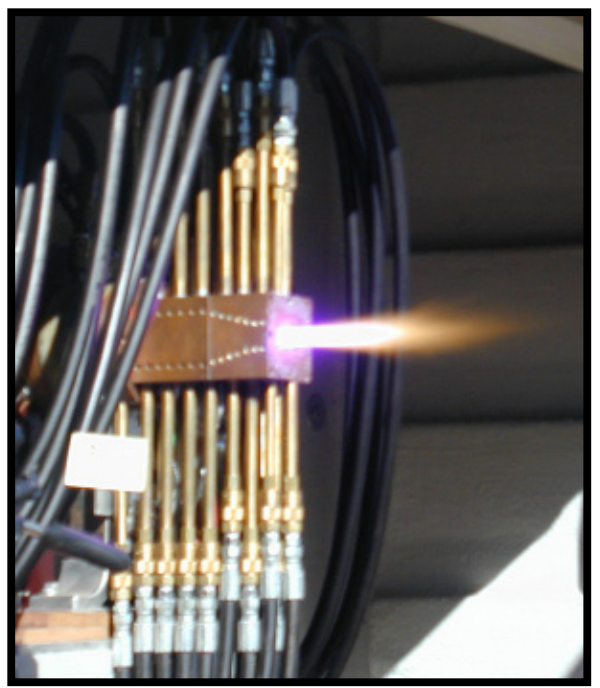

Entrance Flow Path Assembly

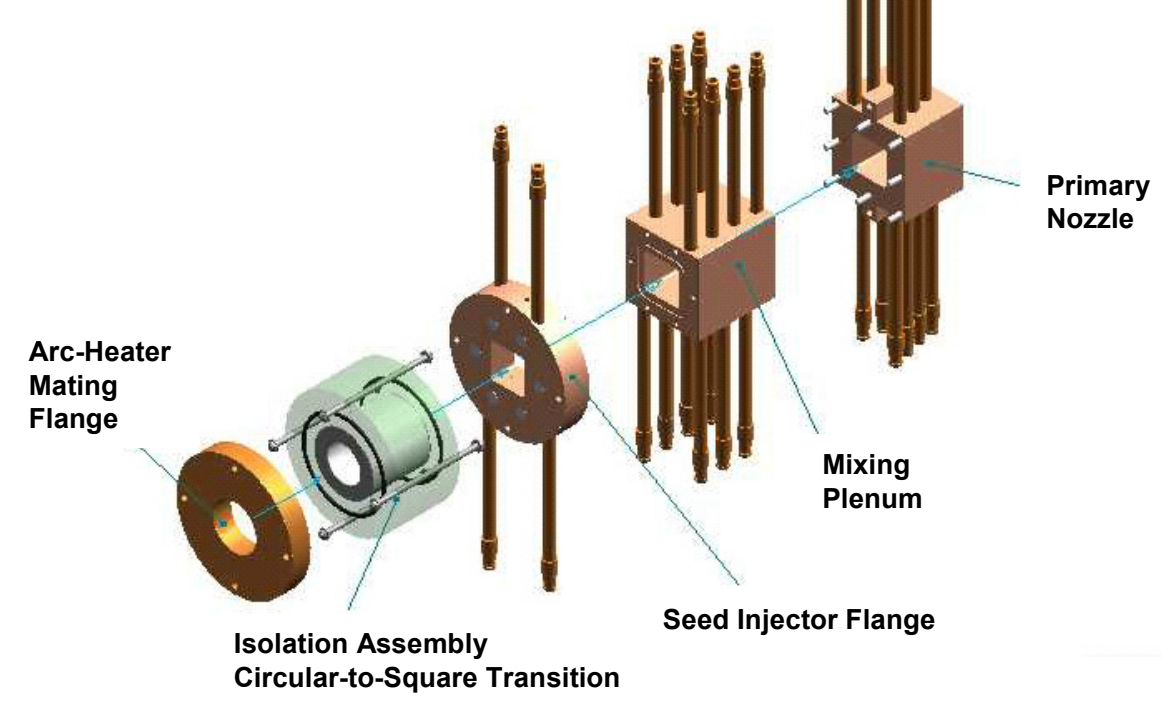

- Performance Verification Testing

$-1.1 \mathrm{MW}_{\mathrm{e}}$ design point condition

- Short duration runs (<10 seconds)

— Nozzle Losses $<20 \%$ 


\section{Electromagnet Characteristics}

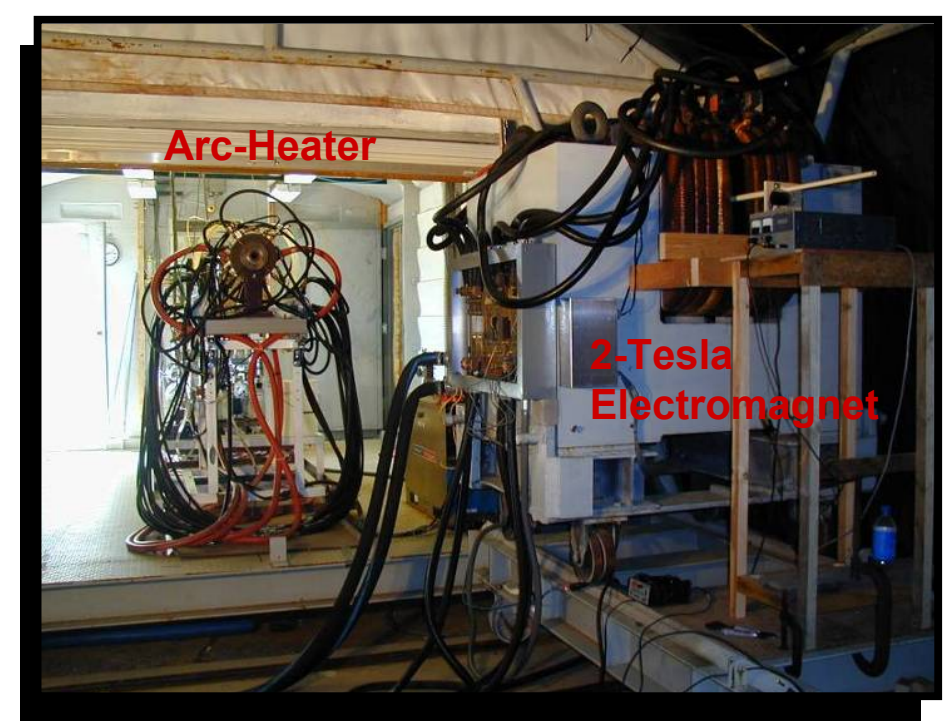

- Electromagnet Performance Specifications

- 2-tesla (maximum)

- 4-inch air gap / 36-inch length

- 2400 amps / 65 volt DC power

- $50 \mathrm{gpm} / 70$ psig cooling water

-12 tons weight
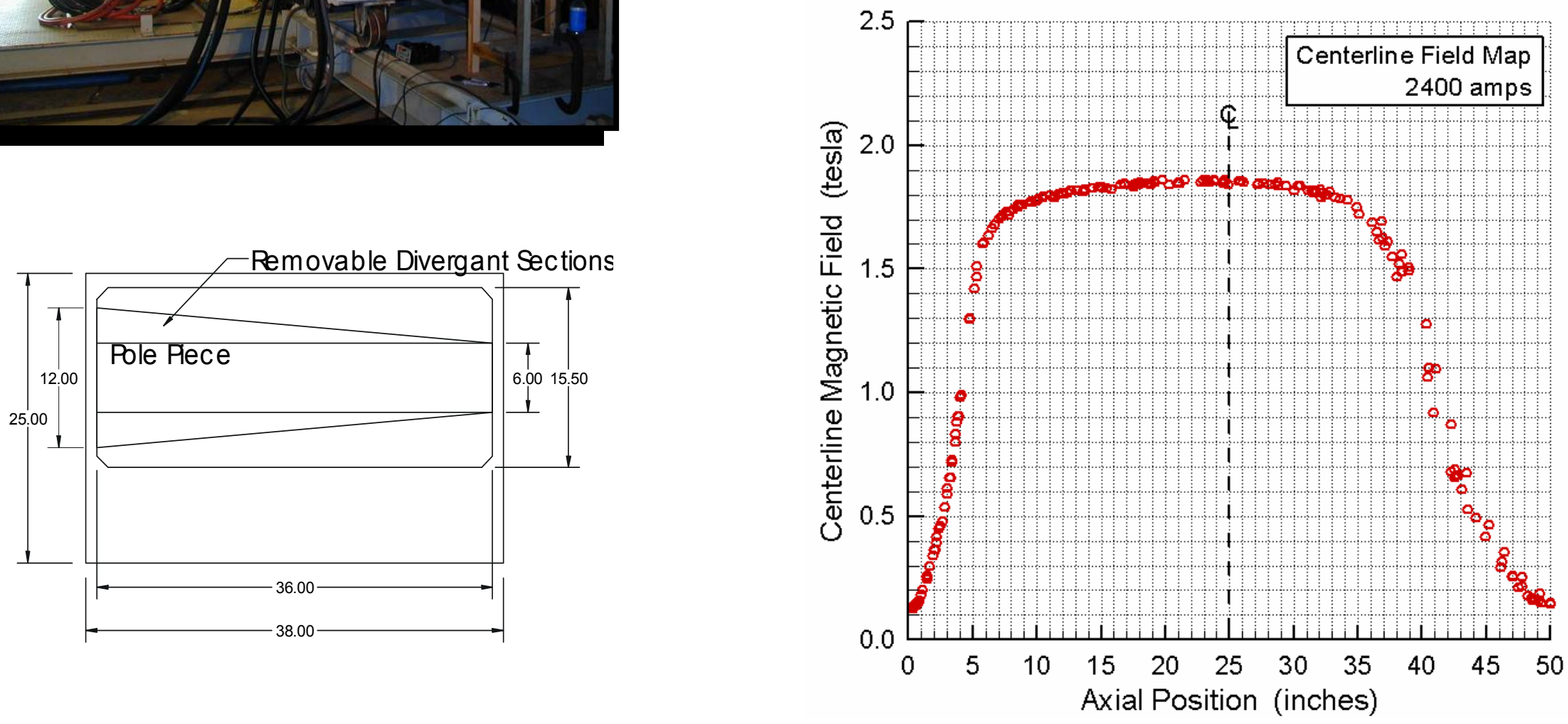


\section{Engineering Design/Performance}

Marshall Space Flight Center

- Engineering Model

- Quasi-1D linear MHD channel analysis

- Legacy engineering MHD code

- Includes major non-ideal effects

- Boundary layer wall functions

- Chemical equilibrium

- Real gas equation of state

- Electrical transport properties

- Non-uniform plasma (G-factor)

- Linear generator \& accelerator modes

- Faraday, Hall, \& Diagonal configurations

- Anchored in historical generator data

\section{Series Connected Diagonal Configuration}

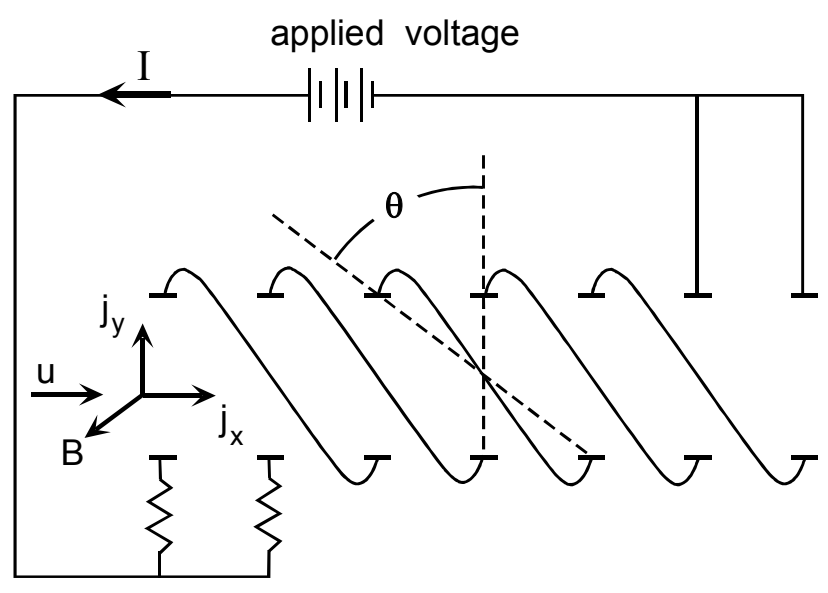

\section{ACCELERATOR DESIGN PROCEDURE}

1. Definition of Characteristics and Operation of Driver Arc Heater Capacity / Efficiency / Composition Defintion of Demonstrated Heating and Pressure Levels (Data) Defintion of Accelerator Design Point Range

2. Scaling Studies

Map Arc Heater Thermodynamics - T vs Q vs $\eta_{e}$

Scale Definiton - Po vs $A^{\star}$ vs m

Map Expansion Thermodynamics - Po, To vs $(\mathrm{P}, \mathrm{T}, \mathbf{M}, \mathbf{A})_{\text {in }}$

Map Expansion Plasmadynamics - $\sigma$ vs $M_{i n}$ \% \%seed

Defintion of Design Point - Po, $m, \sigma \&$ max $\sigma u^{2}$

3. Accelerator Performance/Operation Parametric Design Studies Exercise Accelerator Design Code

- Entrance State - Faraday Loading - Thermo Profile - Loft Pertubate Losses: Q, Cf, G, Vd

Gage Perf: Po \& u Increase, M(x), Jy \& Ex Stress, Power

4. Loading Configuration

Defined Faraday - Replicate Performance for Hall / Diagonal Define Hall Accelerator Operation (Loading)

Define Ideal Reverse Diagonal Operation ( Approximate Reverse Diagonal Operation ( $\theta \mathrm{w}$ average)

5. Finalize Performance Design

Aspect Ratio / Length / End Regions / PTO

Finite Segementation Considerations

Interframe Electrical Leakage

Off-Design Sensitivity

6. Mechanical Design Specifications

Geometry / Loading / Pitch / Heat Sink Mass

Other: PTO / Power Specs / etc. 


\section{MAPX - Design Specifications}

- Iterative Design Calculations

- Optimized MHD acceleration

- Highly sensitive to viscous shear level

- Heat Sink Design

- Graphite electrodes

- Alumina insulators

Table II. MAPX Accelerator Specifications

\begin{tabular}{lc}
\hline Inlet Height $\times$ Width $\left(\mathrm{cm}^{2}\right)$ & $1.6 \times 1.6$ \\
Channel Divergence $($ degrees $)$ & 1.0 \\
Electrode Width $(\mathrm{cm})$ & 1.0 \\
Insulator Width $(\mathrm{cm})$ & 0.5 \\
Active Length $(\mathrm{cm})$ & 90 \\
Powered Electrodes $\left(\mathrm{N}_{\mathrm{p}}\right)$ & 60 \\
Total Length $(\mathrm{cm})$ & 96 \\
Total Electrodes $(\mathrm{N})$ & 65 \\
Exit Height $\times$ Width $\left(\mathrm{cm}^{2}\right)$ & $3.6 \times 3.6$ \\
Seed $(\%$ NaK) & 1.5 \\
$N_{1}$ trogen Flow Rate $(\mathrm{g} / \mathrm{s})$ & 130 \\
$\mathrm{~T}_{0, \text { in }}(\mathrm{K})$ & 3120 \\
$\mathrm{P}_{0, \text { in }}(\mathrm{atm})$ & 8.5 \\
$\mathrm{u}_{\text {in }}(\mathrm{m} / \mathrm{s})$ & 1312 \\
$\sigma_{\text {in }}(\mathrm{S} / \mathrm{m})$ & 25 \\
$\beta_{\text {in }}$ & 0.7 \\
\hline
\end{tabular}

Heat-Sink MHD Channel Assembly
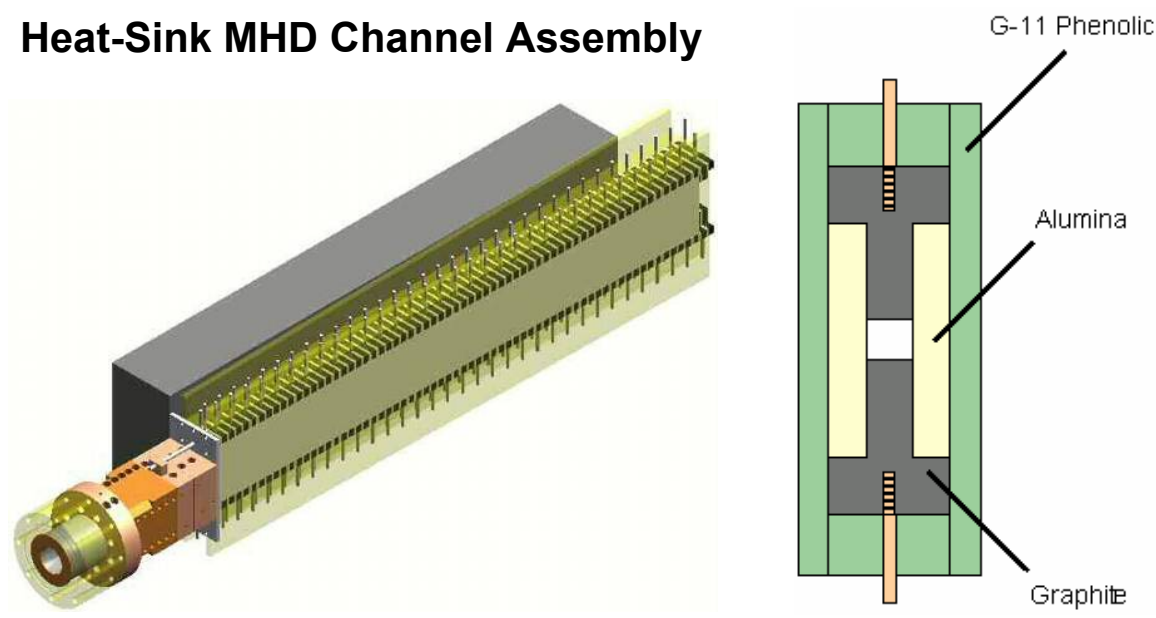

Segmentation Detail

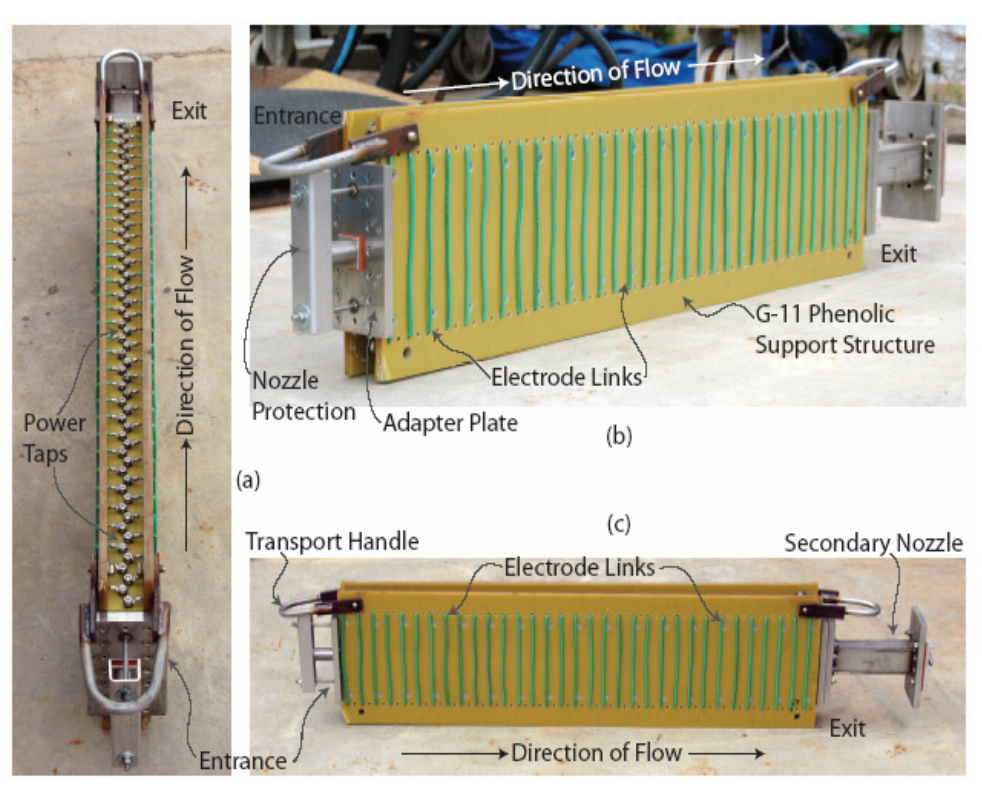




\section{MAPX - Optimal Configuration}

- Diagonalization

- Optimum near $\theta \approx-45^{\circ}\left(j_{x}\right.$ neutralized $)$

- Finite segmentation imposes limits

- 2-electrode offset

- 3-electrode offset

- Power Take-off

- Evenly distribute current in/out

- Practical electrode current density limit

- Avoid MHD compression at inlet

-5 anode leads / 2 cathode leads

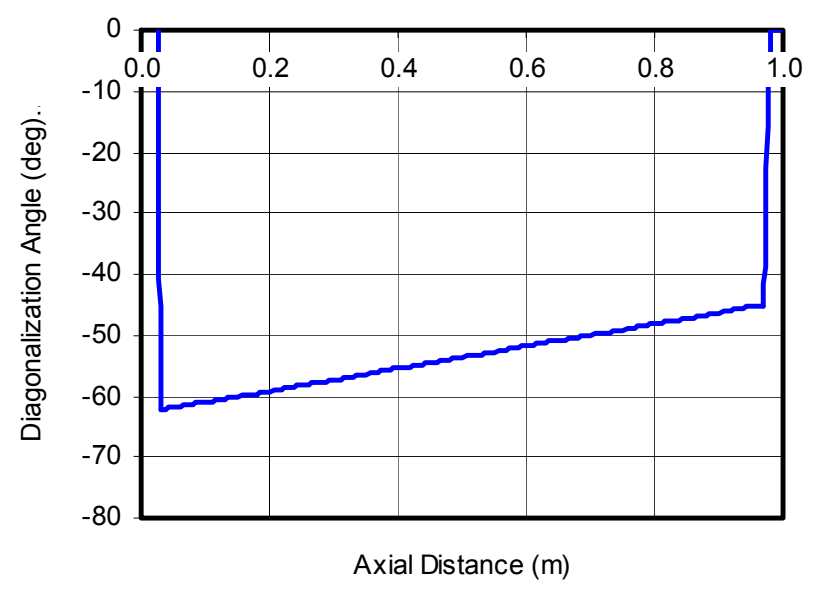

3-Electrode Offset
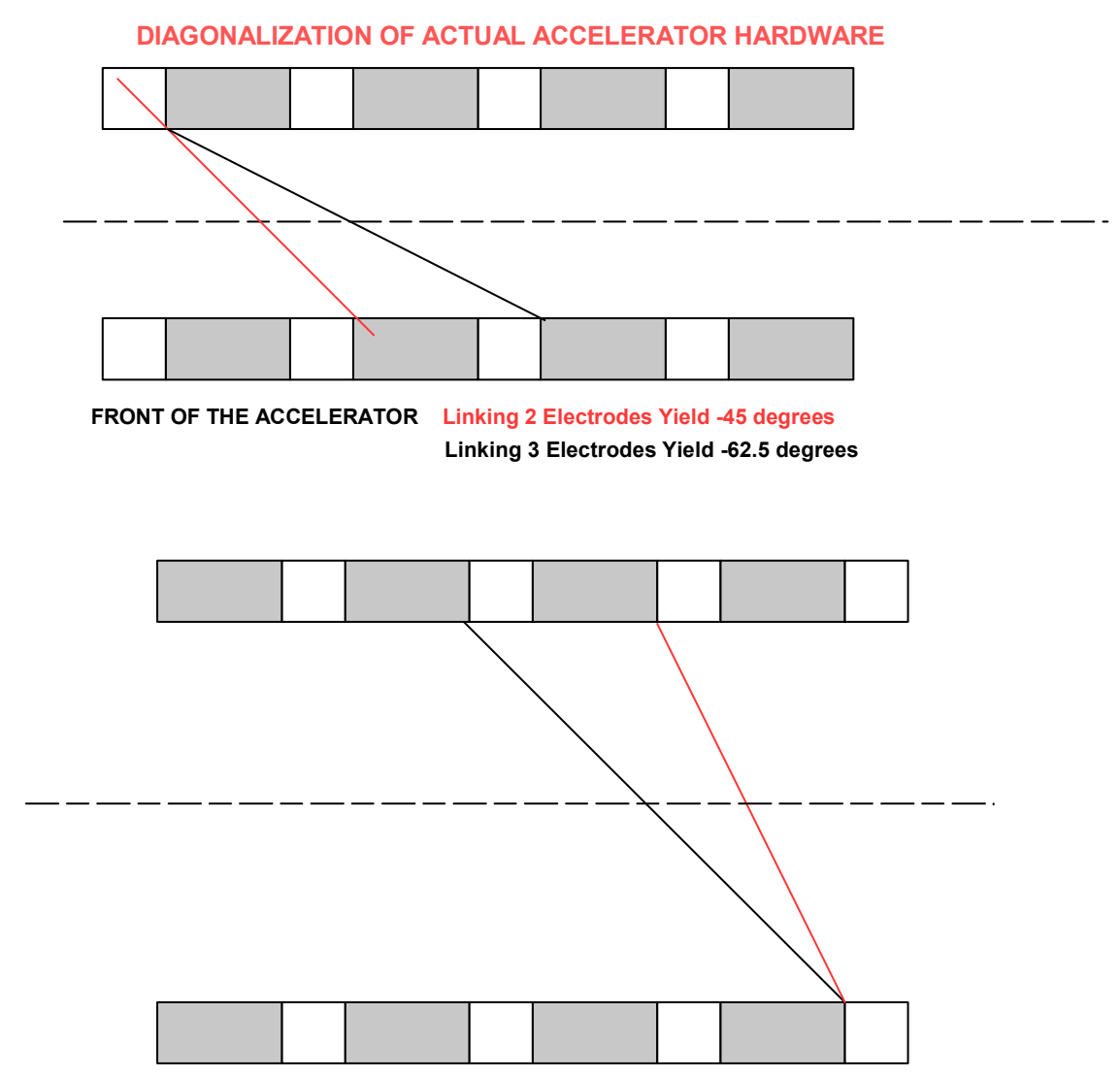

BACK END OF THE ACCELERATOR Linking 2 Electrodes Yield -26.1 degrees Linking 3 Electrodes Yield -45 degrees

DECISION WAS TO LINK 3 ELECTRODE IN CONFIGURATION INDICATED. THIS PRODUCES A WALL ANGLE VARIATION FROM 62.5 TO 45 DEGREES 


\section{MAPX Performance Estimates}
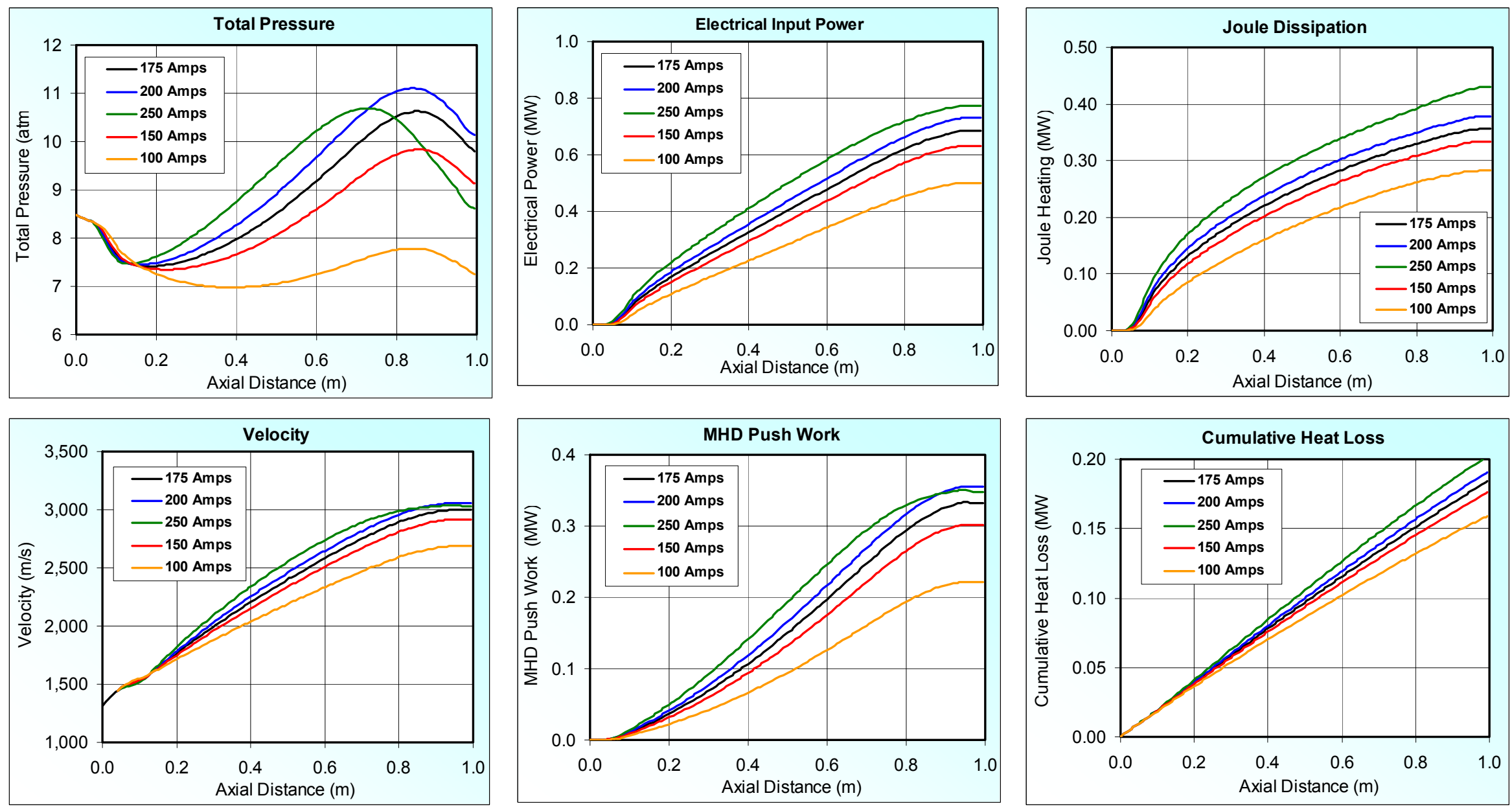


\section{MAPX Performance Estimates}
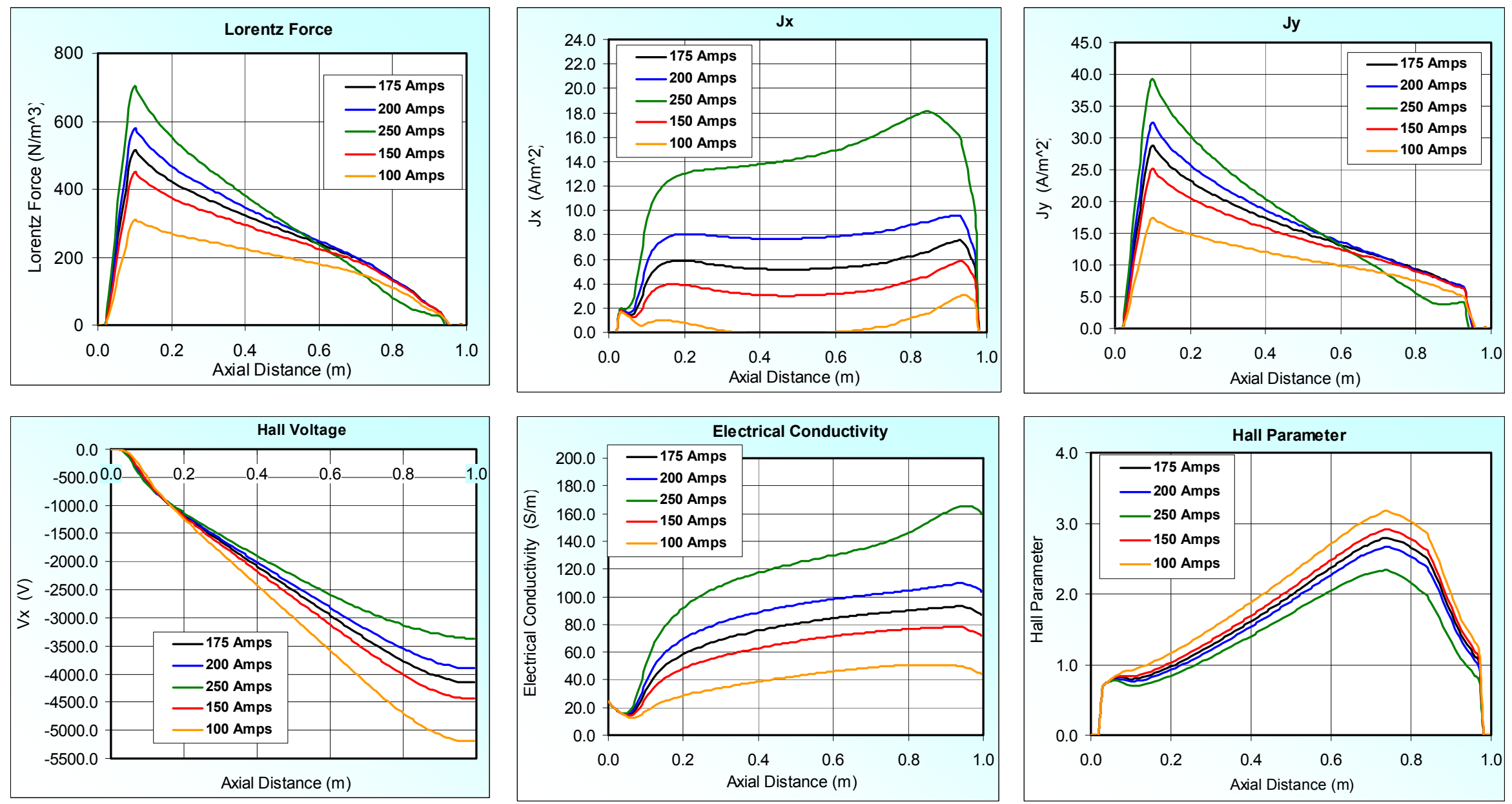


\section{MAPX Performance Estimates}

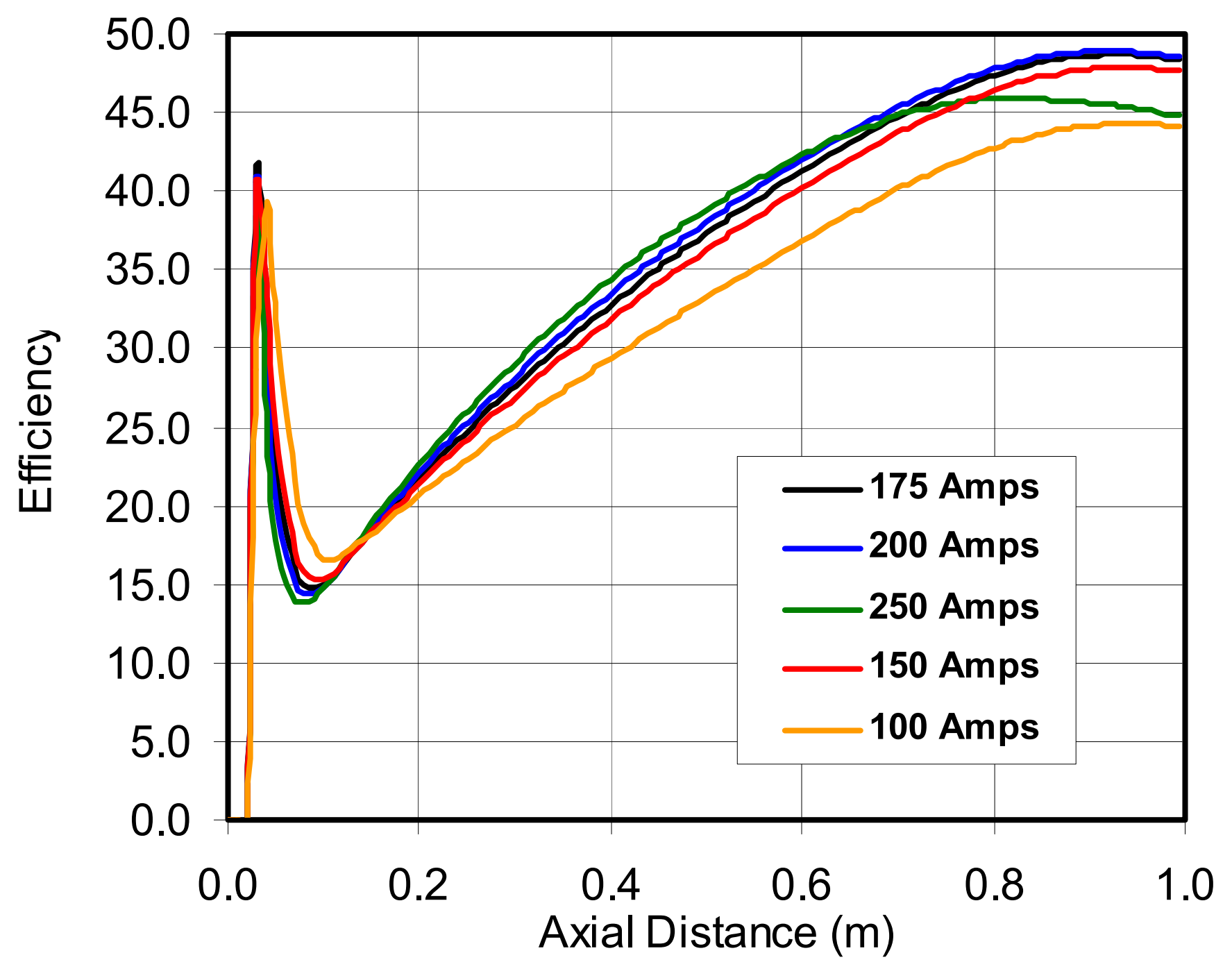




\section{Status - NaK Feeder Design \& Development}

- NaK Feeder System

- Coaxial injector design

- NaK - center post (1/16" SS tube)

- Argon - shroud flow (1/8" SS tube)

- Flow rate calibration

$$
\dot{m} \propto \sqrt{\rho \Delta p}
$$
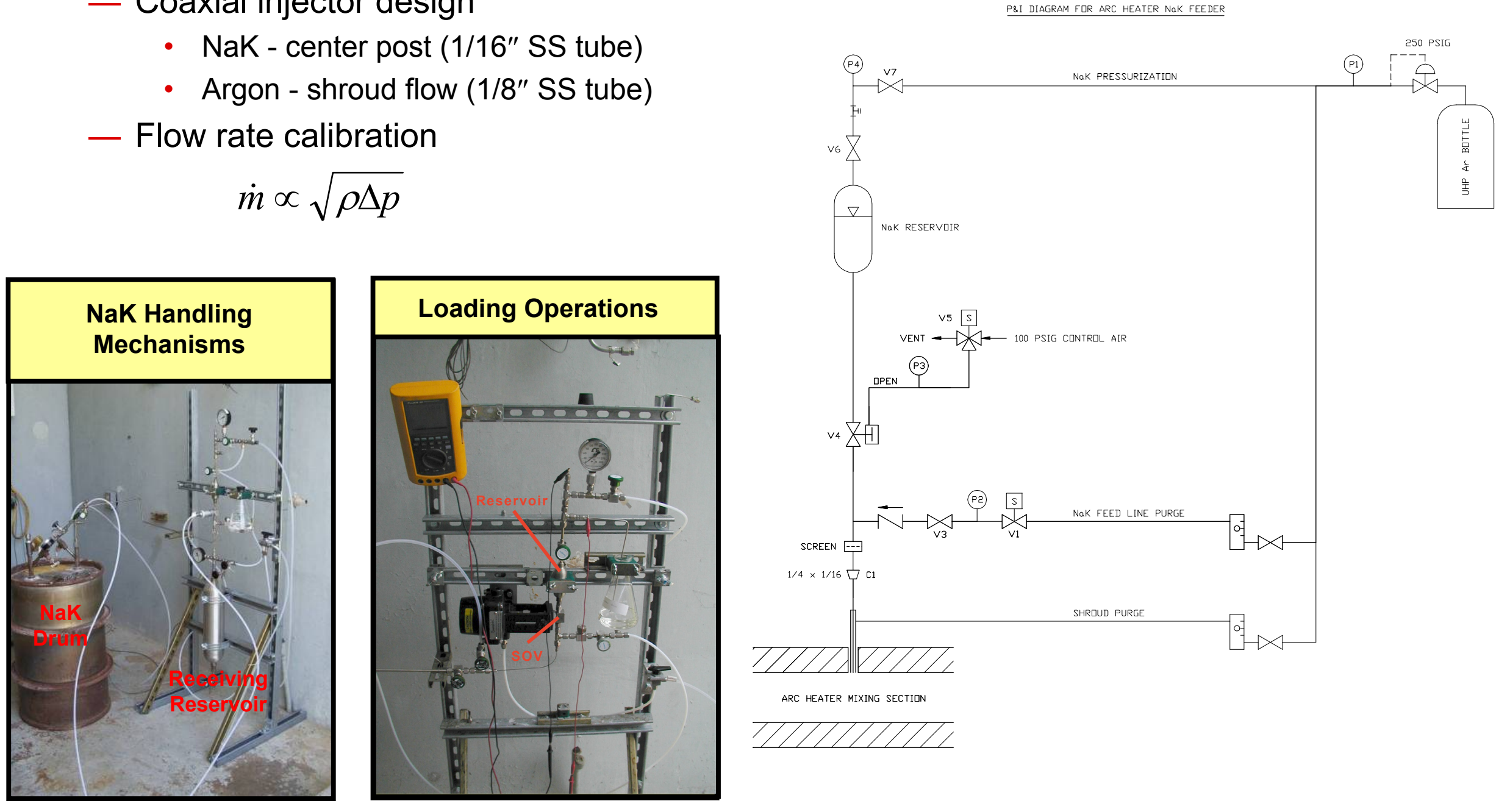


\section{NaK Feeder Calibration}

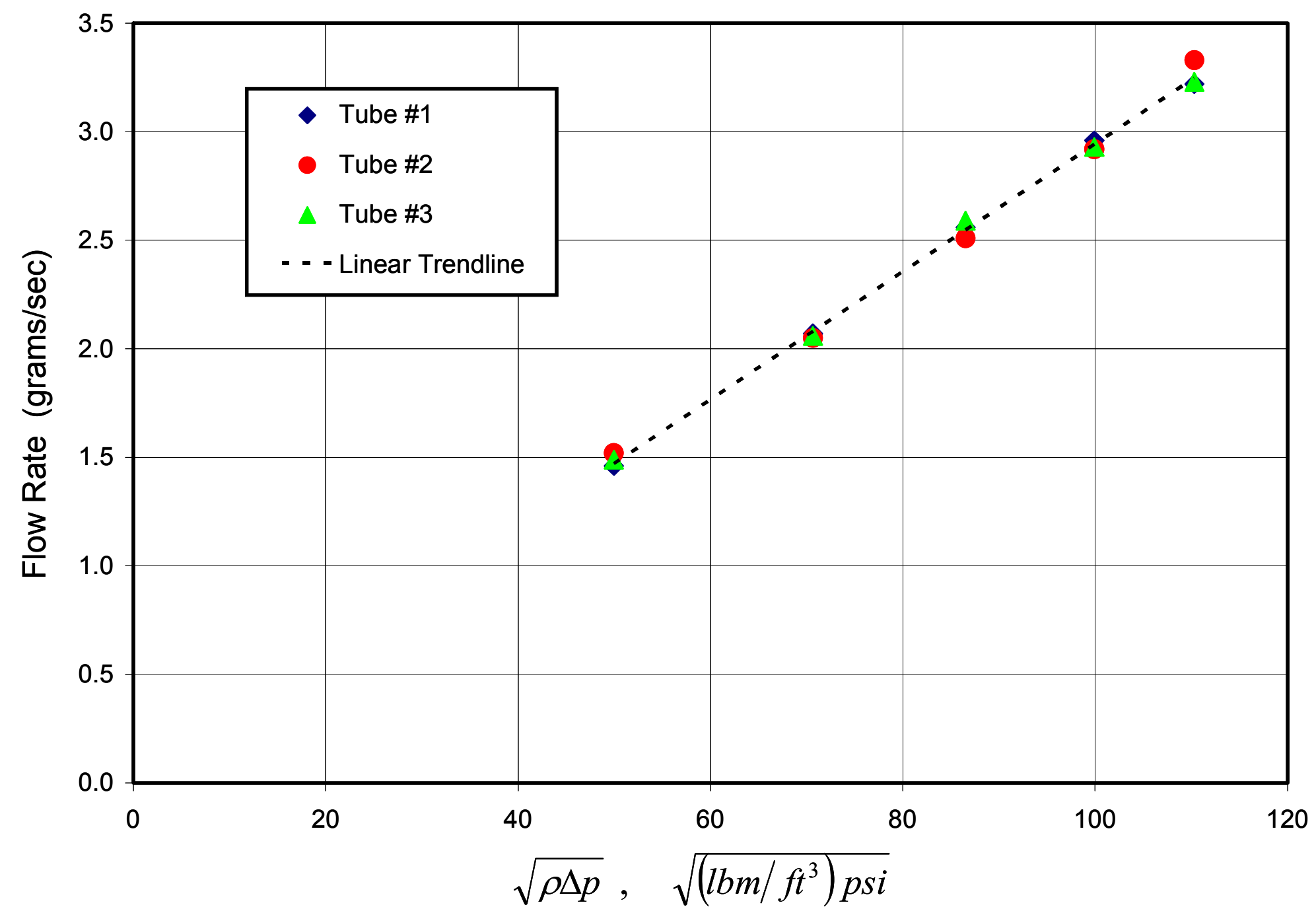




\section{NaK Feeder Verification Testing}

- NaK Feeder Testing

- Characterize free-jet plasma

- ionization / uniformity

— Diagnostics

- High-speed digital video imaging

- polychromatic MW interferometer

- 70/90/110 GHz

- electron number density
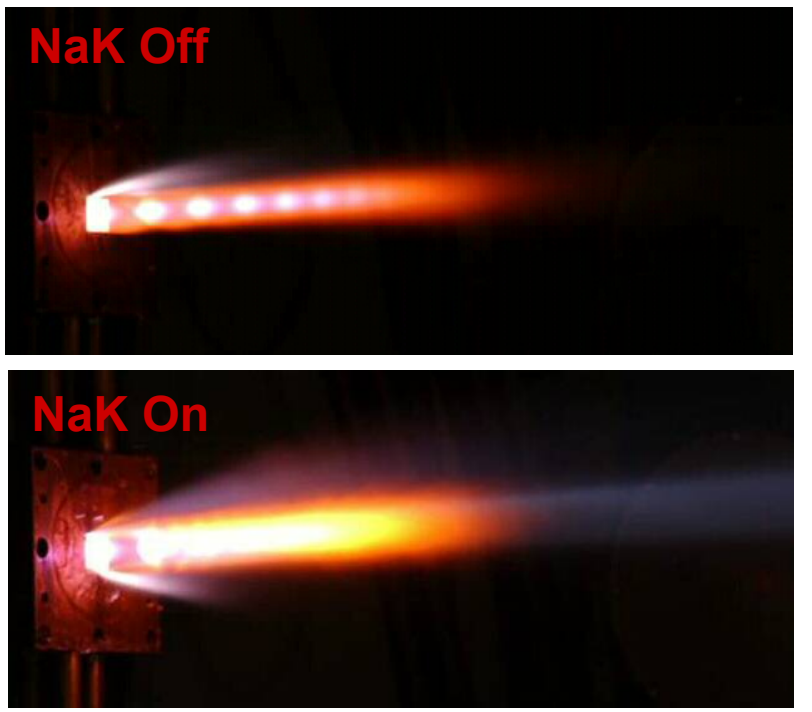
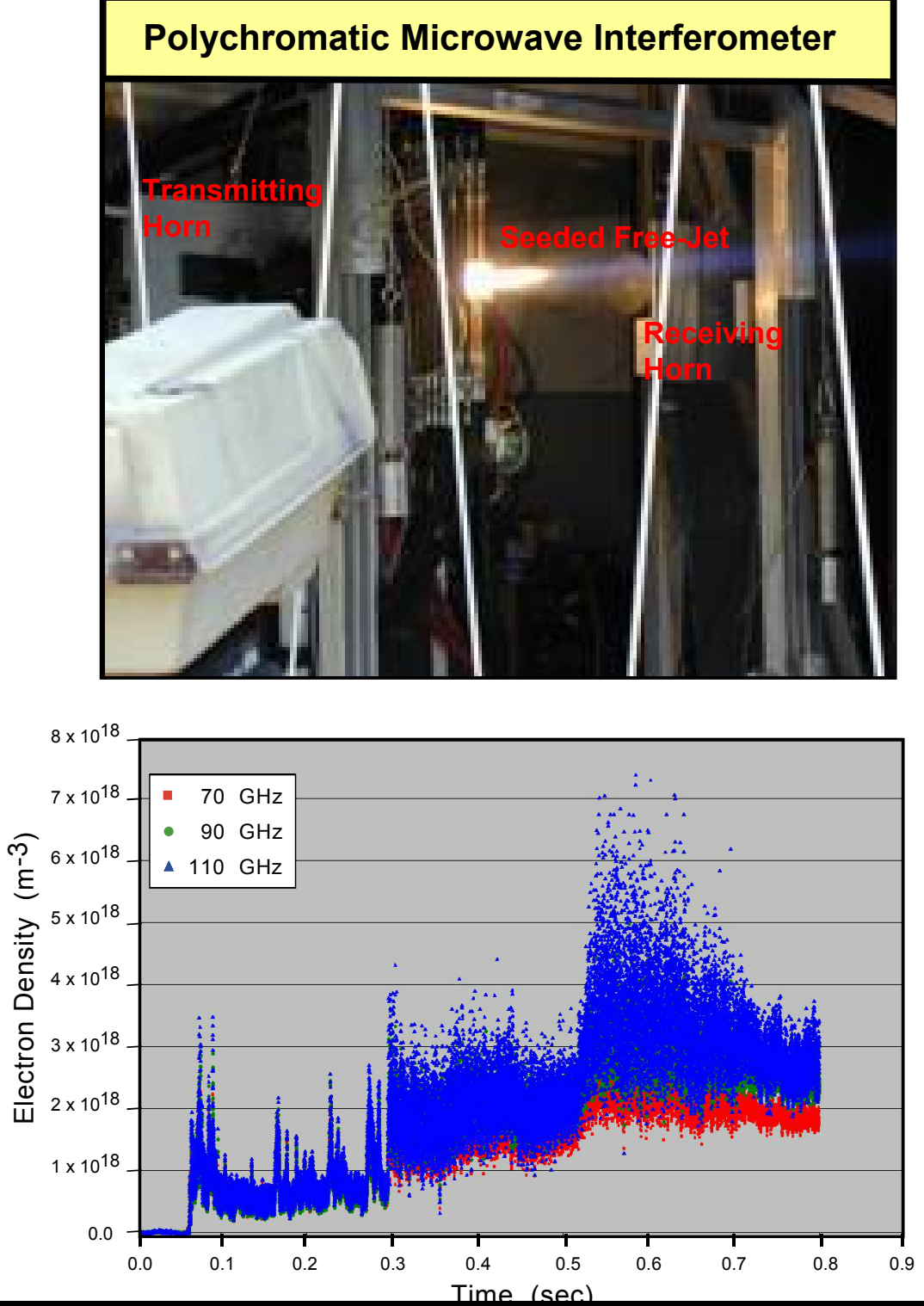


\section{Status - Power Supply Subsystems}

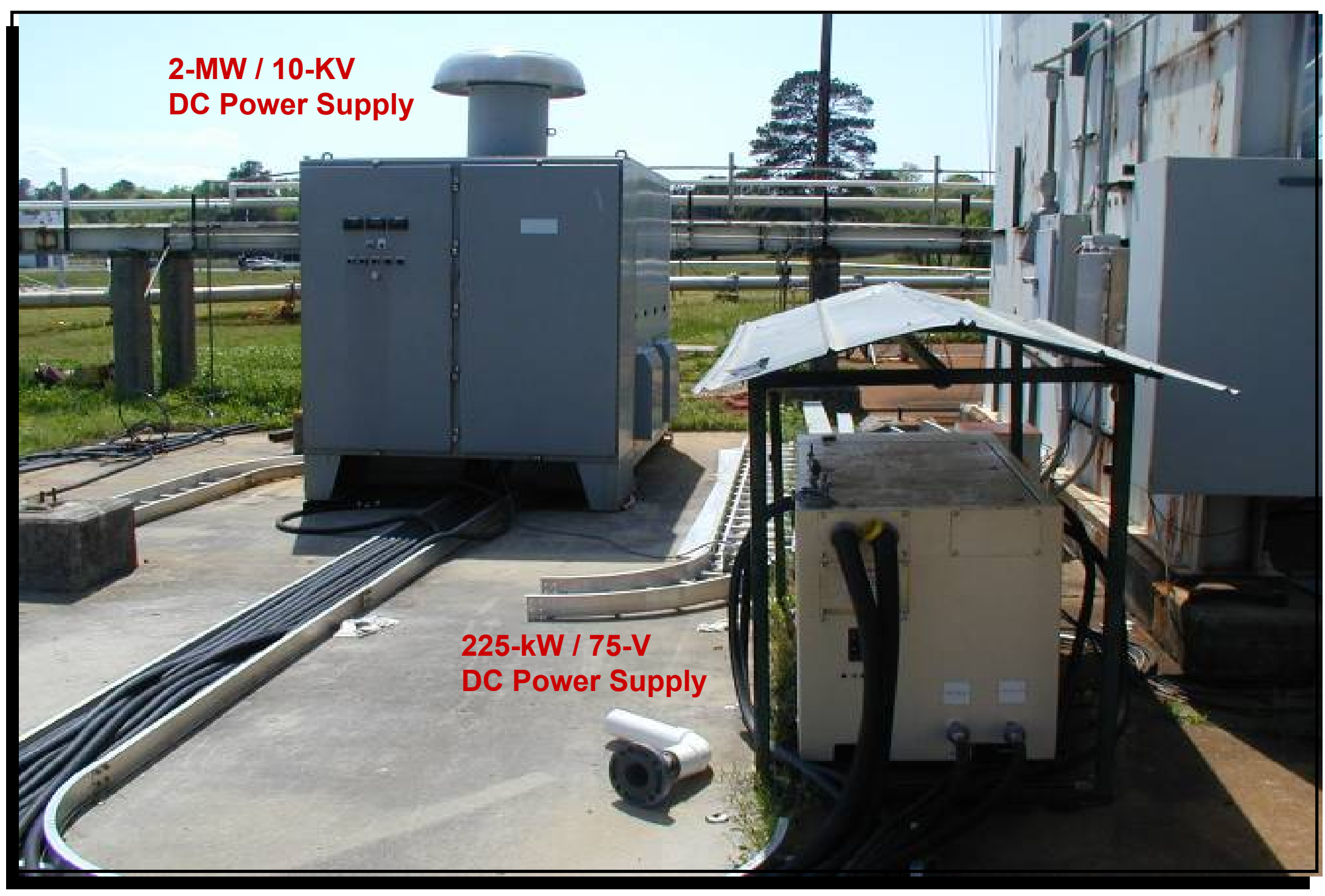




\section{Status - Test Section Cabin \& $\mathbf{N}_{\mathbf{2}}$ Ejector Pump}

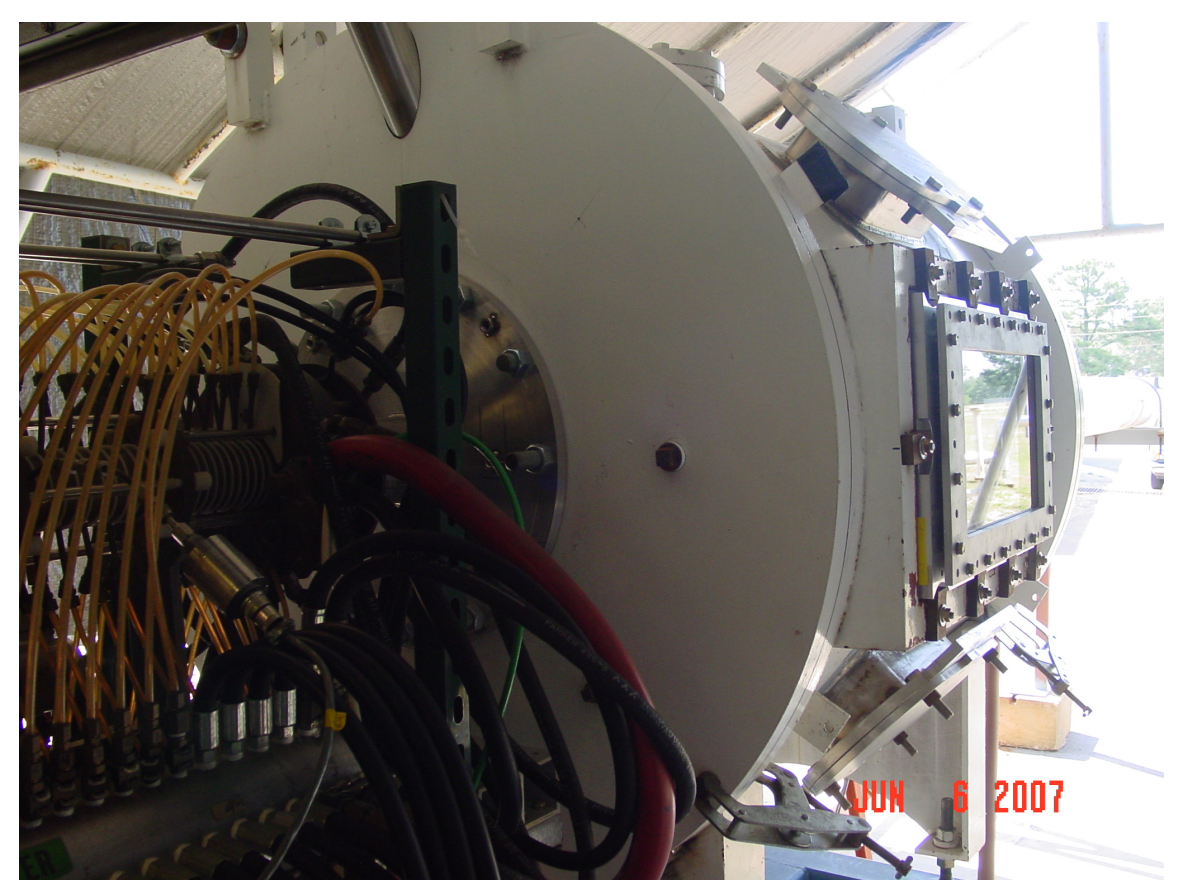

Windowed Test Section Cabin

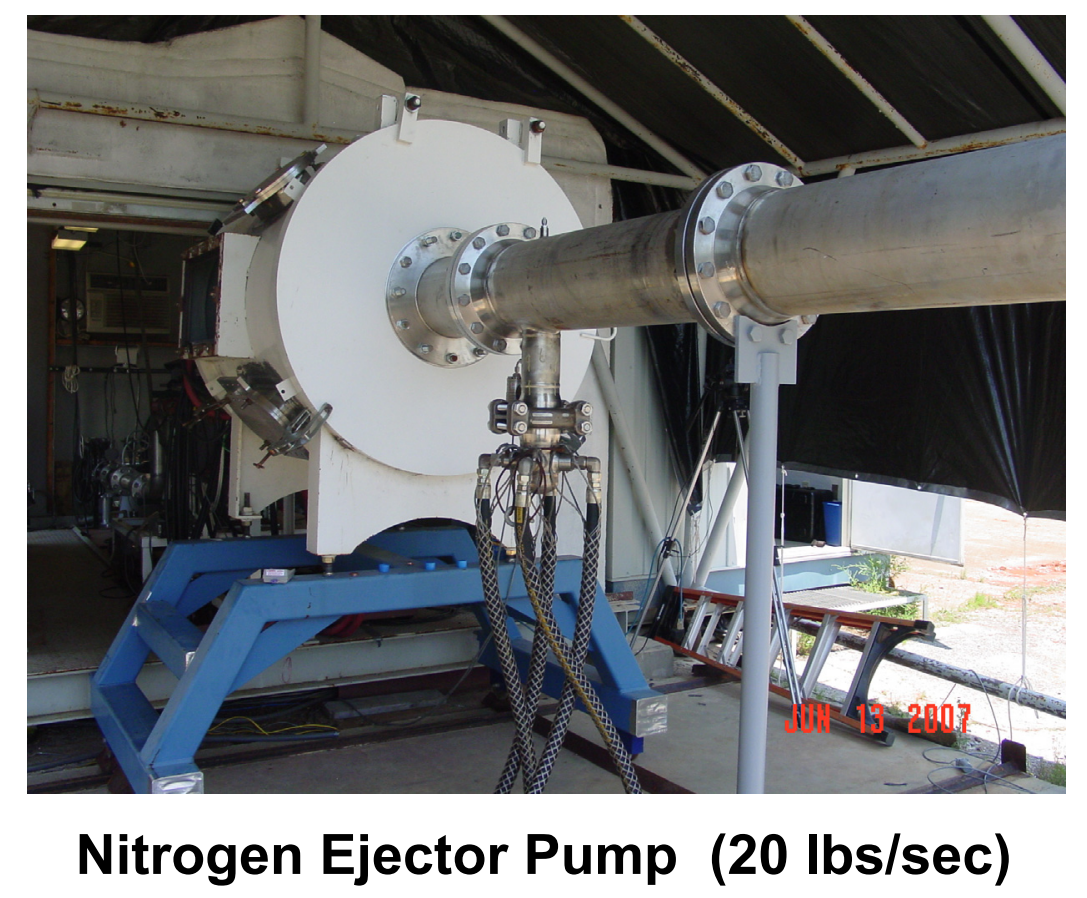




\section{Nitrogen Ejector Pump Performance Characteristics}

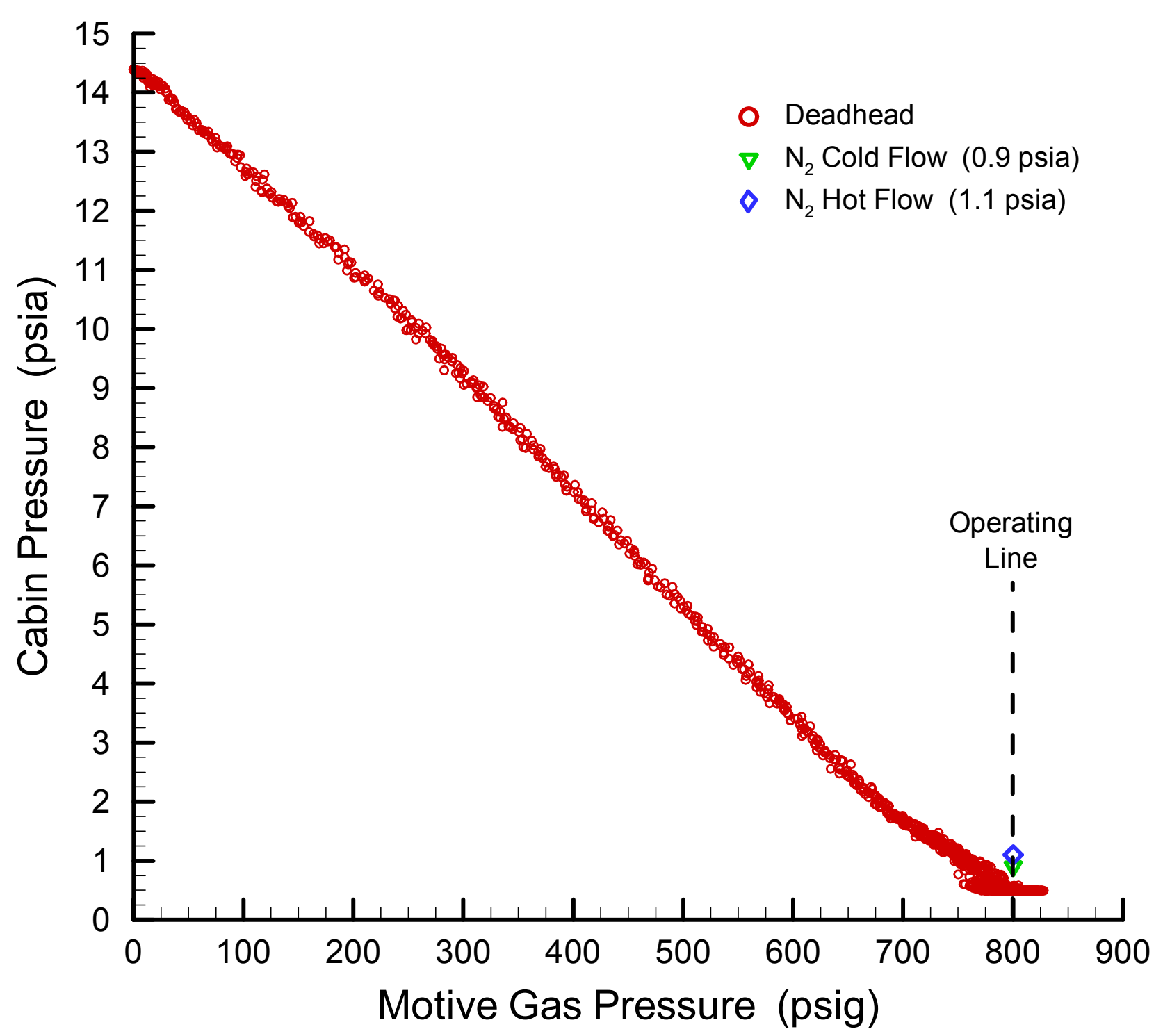




\section{MAPX Test Assembly - November 2008}
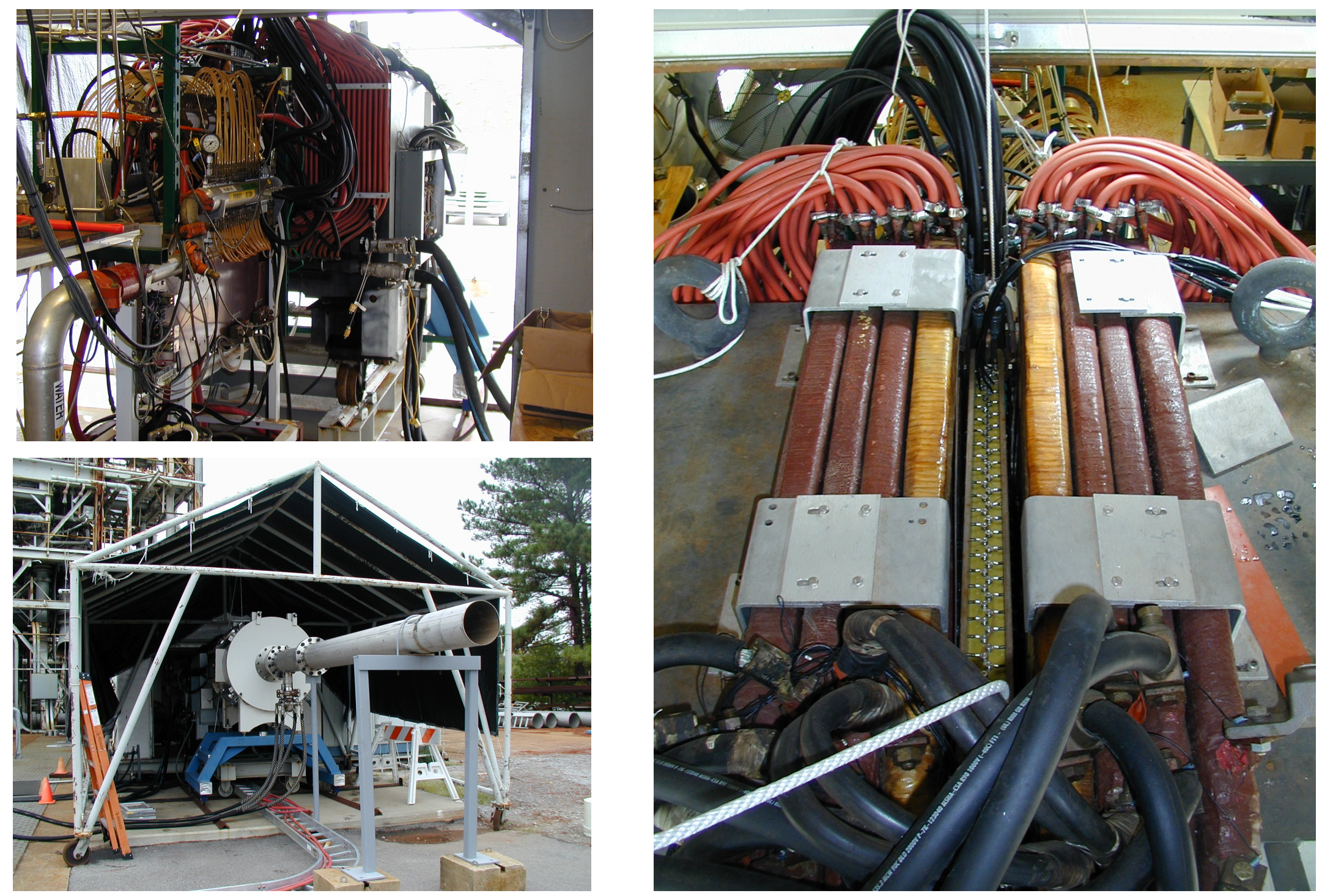


\section{Pitot Probe}

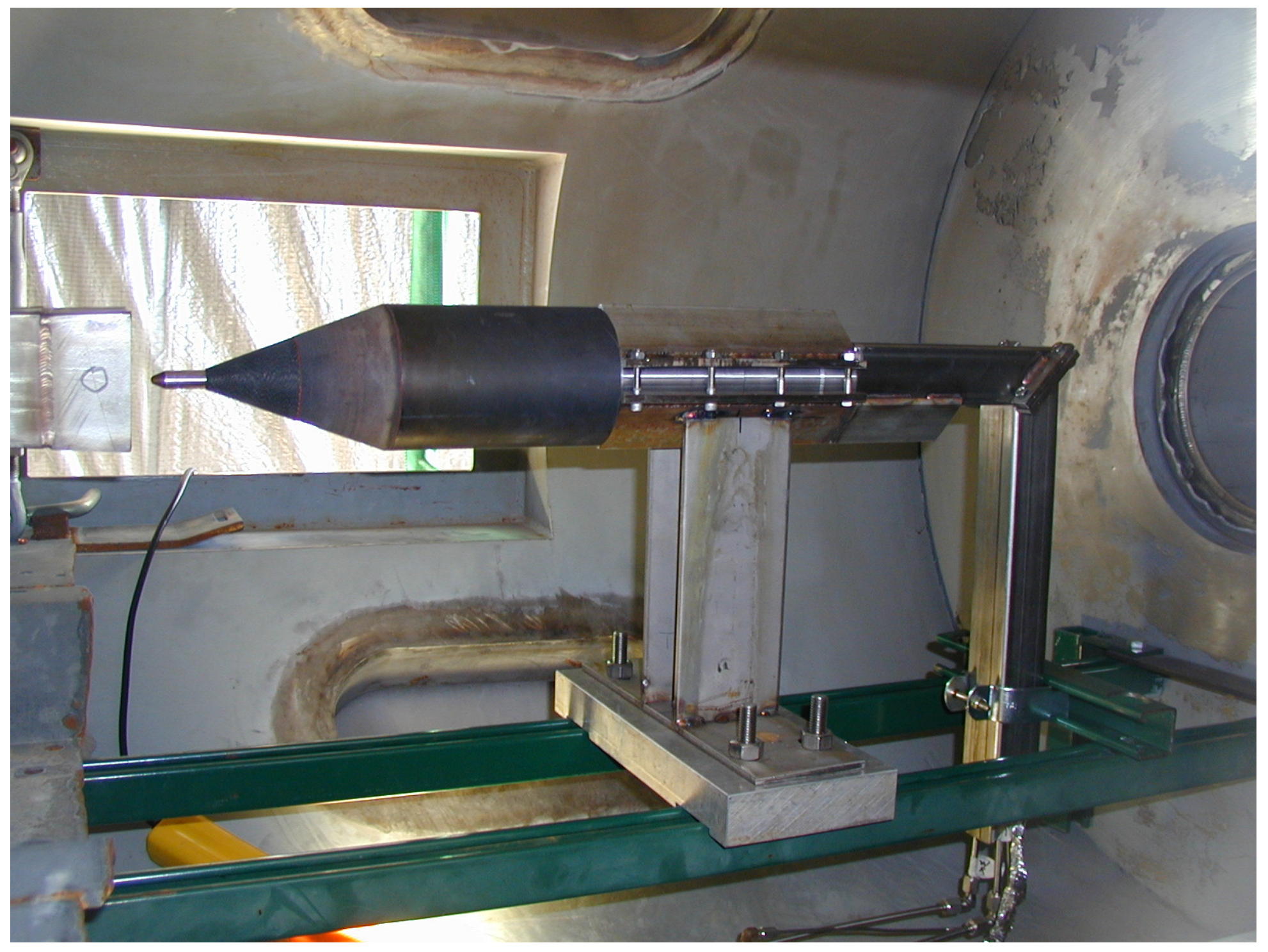




\section{MAPX Test: 16 November 2007}

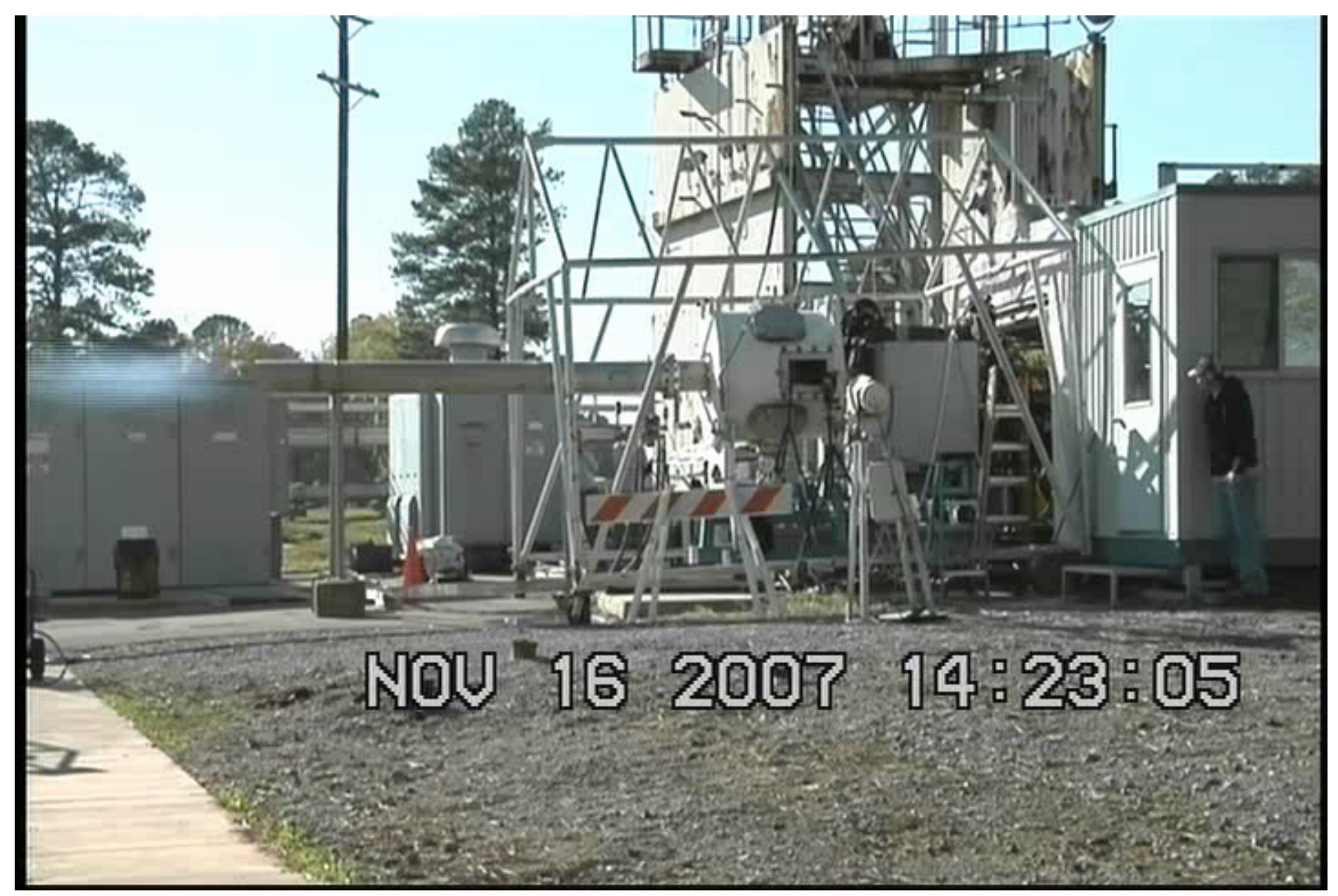




\section{MAPX Test: 16 November 2007}
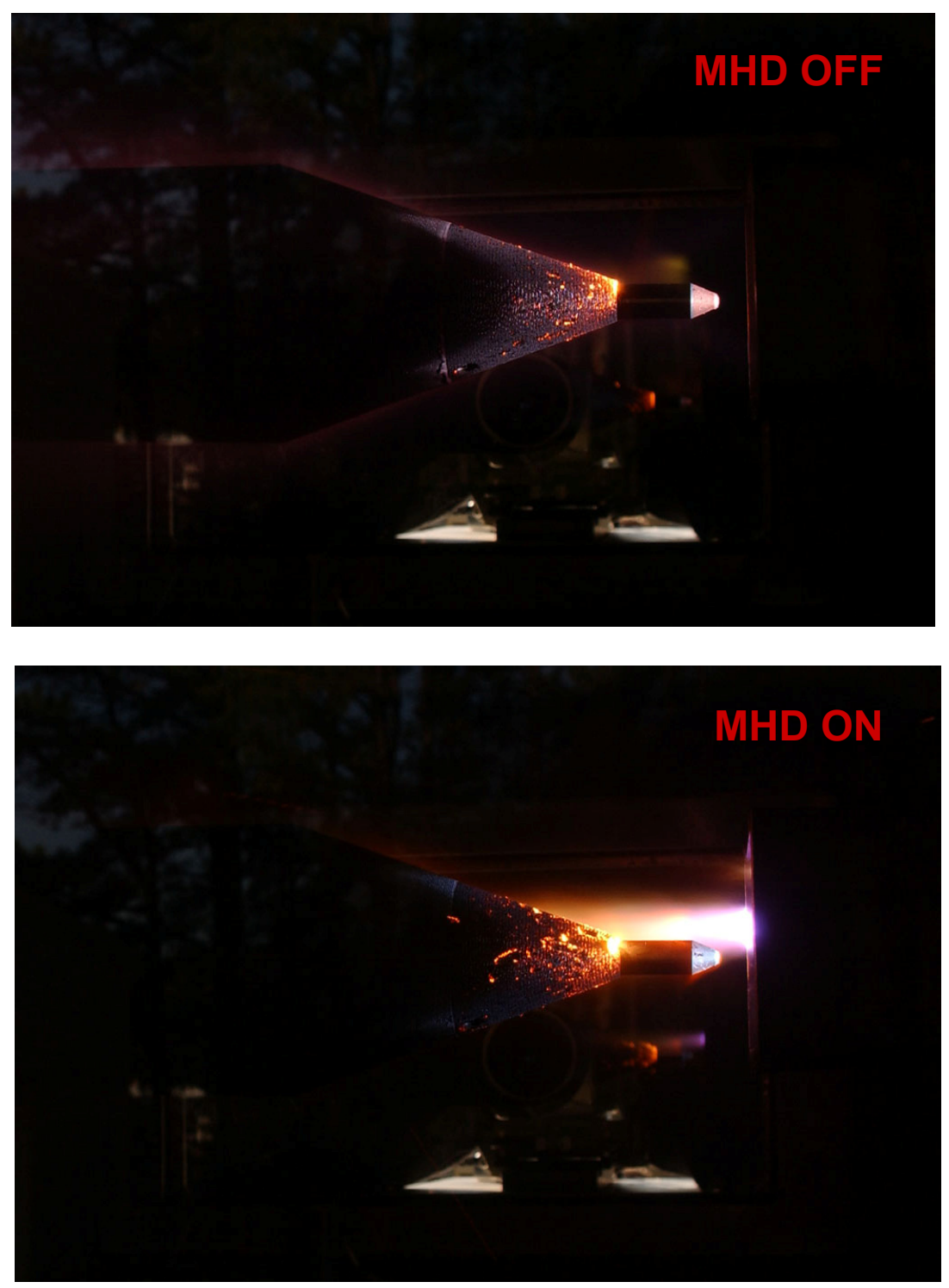


\section{Summary Remarks}

- Experiment Design Complete

- Hardware Fabrication Complete

- Power Supplies Installed

- Component/Sub-System Verifications Testing Complete

- Pre-Test Performance Optimization Analysis Complete

- Full-Up Demonstration Complete

- Post Test Analysis Ongoing

- Publication of Results

- 39 $9^{\text {th }}$ AIAA Plasmadynamics \& Lasers Conference, June 2008 